\title{
Microbial Volatile-Induced Accumulation of Exceptionally High Levels of Starch in Arabidopsis Leaves Is a Process Involving NTRC and Starch Synthase Classes III and IV
}

\author{
Jun Li, ${ }^{1}$ Ignacio Ezquer, ${ }^{1}$ Abdellatif Bahaji, ${ }^{1,2}$ Manuel Montero, ${ }^{1}$ Miroslav Ovecka, ${ }^{1.3}$ \\ Edurne Baroja-Fernández, ${ }^{1}$ Francisco José Muñoz, ${ }^{1}$ Ángel Mérida, ${ }^{4}$ Goizeder Almagro, ${ }^{1}$ \\ Maite Hidalgo, ${ }^{1}$ María Teresa Sesma, ${ }^{1}$ and Javier Pozueta-Romero ${ }^{1}$ \\ ${ }^{1}$ Instituto de Agrobiotecnología (CSIC/UPNA/Gobierno de Navarra). Mutiloako etorbidea z/g, 31192 Mutiloabeti, Nafarroa, \\ Spain; ${ }^{2}$ Iden Biotechnology S.L., Av. Conde Oliveto 2, 3I, 31002 Pamplona, Nafarroa, Spain; ${ }^{3}$ Institute of Botany, Slovak \\ Academy of Sciences, Dubravska cesta 9, SK-84523 Bratislava, Slovakia; ${ }^{4}$ Instituto de Bioquímica Vegetal y Fotosíntesis. \\ CSIC-US. Avda Américo Vespucio, 49. 41092-Sevilla, Spain
}

Submitted 5 May 2011. Accepted 1 June 2011.

Microbial volatiles promote the accumulation of exceptionally high levels of starch in leaves. Time-course analyses of starch accumulation in Arabidopsis leaves exposed to fungal volatiles (FV) emitted by Alternaria alternata revealed that a microbial volatile-induced starch accumulation process (MIVOISAP) is due to stimulation of starch biosynthesis during illumination. The increase of starch content in illuminated leaves of FV-treated hy1/cry1, hy1/cry2, and hy1/cry1/ cry 2 Arabidopsis mutants was many-fold lower than that of wild-type (WT) leaves, indicating that MIVOISAP is subjected to photoreceptor-mediated control. This phenomenon was inhibited by cordycepin and accompanied by drastic changes in the Arabidopsis transcriptome. MIVOISAP was also accompanied by enhancement of the total 3-phosphoglycerate/Pi ratio, and a two- to threefold increase of the levels of the reduced form of ADP-glucose pyrophosphorylase. Using different Arabidopsis knockout mutants, we investigated the impact in MIVOISAP of downregulation of genes directly or indirectly related to starch metabolism. These analyses revealed that the magnitude of the FVinduced starch accumulation was low in mutants impaired in starch synthase (SS) classes III and IV and plastidial NADP-thioredoxin reductase C (NTRC). Thus, the overall data showed that Arabidopsis MIVOISAP involves a photocontrolled, transcriptionally and post-translationally regulated network wherein photoreceptor-, SSIII-, SSIV-, and NTRC-mediated changes in redox status of plastidial enzymes play important roles.

Plants produce starch as the predominant storage carbohydrate to cope with temporary starvation imposed by the environment. In leaves, starch is synthesized in the chloroplast during the day from photoassimilated carbon and degraded throughout the following night to support metabolism. This branched homopolysaccharide is produced by starch synthase (SS) using ADP-

Corresponding author: J. Pozueta-Romero; Telephone: (34) 948168009; Fax: (34) 948232191; E-mail: javier.pozueta@ unavarra.es

* The $e$-Xtra logo stands for "electronic extra" and indicates that four supplementary figures and three supplementary tables are published online. glucose (ADPG) as the sugar donor molecule. Branch points are introduced by branching enzymes, and debranching enzymes are involved in tailoring the branched glucans into a form capable of crystallization. In leaves, starch breakdown is mainly hydrolytic, with maltose and glucose being the major starch-degradation products. As in bacteria, where glycogen acts as a carbon capacitor that regulates the carbon flow through different metabolic pathways in response to physiological needs (Belanger and Hatfull 1999; Guedon et al. 2000; Moreno-Bruna et al. 2001), starch acts as a major integrator of the plant metabolic status, its metabolism involving transcriptional and post-transcriptional regulatory mechanisms (BaenaGonzález et al. 2007; Kleczkowski 1999; Michalska et al. 2009; Sehnke et al. 2001; Smith et al. 2004; Sokolov et al. 1998; Valerio et al. 2010).

Plants perceive biotic stimuli by recognizing a multitude of different signaling compounds originating from the interacting organisms. Some of these substances include carbohydrates, proteins, glycoproteins, peptides, lipids, and sterols that act as elicitors of defense reactions (Hahlbrock et al. 2003). Microbes also synthesize and emit many volatile compounds. Volatile emissions from rhizobacterial isolates of Bacillus subtilis GB03, B. amyloliquefaciens IN937, and B. cepacia promote growth in Arabidopsis plants by facilitating nutrient uptake, photosynthesis, and defense responses, and by decreasing glucose sensing and abscissic acid levels (Paré et al. 2005; Ryu et al. 2003, 2004; Vespermann et al. 2007; Zhang et al. 2008b, 2009). Recently, Kai and Piechulla (2009) have proposed that $\mathrm{CO}_{2}$ emitted by these microbes acts as a plantgrowth-promoting volatile. Physical contact with microorganisms adjusts plant defense reactions and very often leads to a decrease in photosynthesis and a transition from source to sink status in photosynthetic tissues. In some instances, the sucrolytic enzymes invertase and sucrose synthase (SuSy) are upregulated upon microbial contact (Bonfig et al. 2006; Chou et al. 2000; Fotopoulos et al. 2003; Michel et al. 2006; Scharte et al. 2005), which may serve to reduce sucrose export from the infected leaf to other parts of the plant or to promote cell wall polysaccharide biosynthesis at infection sites (Essmann et al. 2008). Physical contact with the pathogen may also result in downregulation of genes involved in starch metabolism (Cartieaux et al. 2008; Fabro et al. 2008), 
which may facilitate the availability of simple sugars for the pathogen at infection sites.

Most studies on plant-microbe interactions have been carried out under conditions of physical contact between the host plant and the microbe. However, little is known about how microbial volatile emissions may affect plant physiology in the absence of physical contact. Given the lack of knowledge regarding how microbial volatiles may affect reprogramming of cellular metabolism in plants (in particular, primary carbohydrate metabolism), we have recently explored the effect on starch metabolism of volatiles released from different microbial species ranging from gram-negative and gram-positive bacteria to different fungi (Ezquer et al. 2010). We found that all microbial species tested (including plant pathogens and microbes normally not interacting with plants) emitted volatiles that strongly promoted starch accumulation in leaves of both mono- and di-cotyledonous plants when microbes were cultured in minimal media (Ezquer et al. 2010). Analyses of potato leaves exposed for 2 days to fungal volatiles (FV) emitted by the plant pathogen Alternaria alternata revealed that this phenomenon, the microbial volatile-induced starch accumulation process (MIVOISAP), was accompanied by dramatic changes in the leaf transcriptome and in activities of starch-related enzymes. To better understand MIVOISAP, in this work, we carried out time-course analyses of starch accumulation in leaves of Arabidopsis plants cultured in the presence or in the absence of FV emitted by A. alternata. We also analyzed transcriptomic changes in leaves of Arabidopsis plants upon FV treatment. In addition, using Arabidopsis T-DNA mutants, we investigated the impact in MIVOISAP of downregulation of genes directly involved in starch metabolism and genes whose expression is altered during MIVOISAP. The overall data showed that Arabidopsis MIVOISAP involves a photocontrolled, transcriptionally and post-translationally regulated network wherein SS class III- and IV- and NADP-Trx reductase (NTRC)-mediated changes in redox status of plastidial enzymes play important roles. Furthermore, we provide evidence that FV treatment activates plastidial $\beta$-amylase-dependent starch degradation during starch overaccumulation.

\section{RESULTS AND DISCUSSION}

\section{Microbial volatiles promote transitory starch biosynthesis during illumination.}

Leaves of plants cultured in a regime of 16 and $8 \mathrm{~h}$ of white light and darkness, respectively, accumulated exceptionally

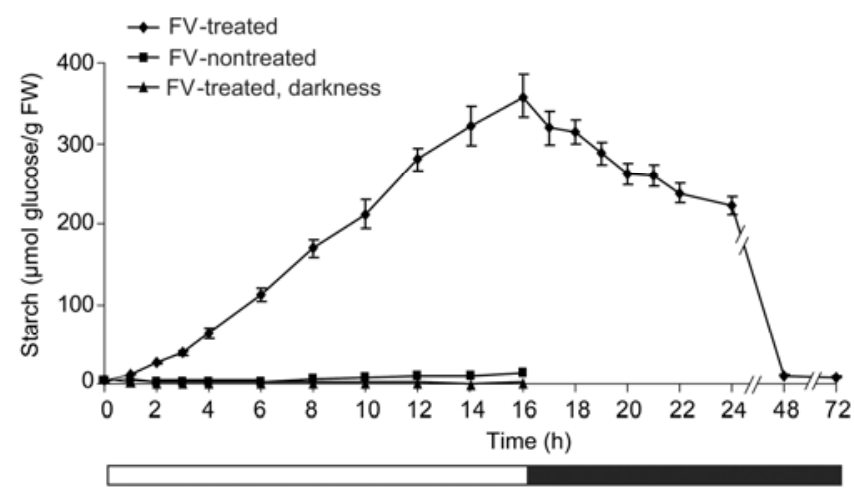

Fig. 1. Time course of starch content in leaves treated of fungal volatiles (FV)-treated and nontreated Arabidopsis plants. Diamonds represent the starch content in leaves of FV-treated plants illuminated for $16 \mathrm{~h}$ with white light and then subjected to darkness for $56 \mathrm{~h}$. Triangles represent the starch content in leaves of FV-treated plants cultured in darkness. Squares represent the starch content in leaves of FV-nontreated plants illuminated for $16 \mathrm{~h}$. Results are the mean \pm standard error of three independent experiments. high levels of starch after 2 days of exposure to FV emitted by A. alternata (Ezquer et al. 2010). To know whether this phenomenon was the result of enhanced starch biosynthesis during illumination or reduced starch breakdown during the dark, we carried out a time-course analysis of starch content in leaves of FV-treated and nontreated Arabidopsis plants cultured in solid Murashige-Skoog (MS)-sucrose for $16 \mathrm{~h}$ of illumination under white light. As control, we measured the starch content in FV-treated plants cultured in solid MS sucrose medium under dark conditions. As expected, these analyses revealed that FV-treated plants did not accumulate starch during darkness (Fig. 1). Illuminated, FV-nontreated plants accumulated starch at a rate approximately $18 \mathrm{nmol}$ of glucose transferred to starch per minute $\times$ gram fresh weight (FW) (Fig. 1). Notably, starch overaccumulation in leaves of illuminated plants was rapidly stimulated by FV treatment (Fig. 1). Judicious examination of the process revealed that the rate of starch accumulation during the initial $2 \mathrm{~h}$ of $\mathrm{FV}$ treatment consisted of glucose transferred to starch at $240 \mathrm{nmol} / \mathrm{min} \times$ gram $\mathrm{FW}$. After $2 \mathrm{~h}$ of exposure to $\mathrm{FV}$, the rate of starch accumulation increased to glucose transferred to starch at $480 \mathrm{nmol} / \mathrm{min} \times$ gram FW, which remained nearly constant during the following $14 \mathrm{~h}$ of FV treatment (Fig. 1). Time-course analyses of starch content during darkness in leaves of plants that had previously been cultured for $16 \mathrm{~h}$ in the presence of FV under white light revealed that starch content declined for glucose removed from starch at a rate of $450 \mathrm{nmol} / \mathrm{min} \times$ gram $\mathrm{FW}$ when plants were cultured in darkness in the presence of FV (Fig. 1). After $32 \mathrm{~h}$ of darkness in the presence of FV, Arabidopsis leaves accumulated very low starch content, which indicates that starch breakdown machinery is active during darkness in FV-treated Arabidopsis leaves.

Thus, the overall data showed that Arabidopsis MIVOISAP is ascribed to stimulation of starch biosynthesis during illumination.

\section{Arabidopsis MIVOISAP is subjected to photoreceptor-mediated control.}

As well as providing the primary source of energy to support photosynthesis, light is one of the most important environmental signals governing many developmental and physiological aspects of plants (Chen et al. 2004). Light acts through photoreceptors to regulate a variety of responses including light-induced reserve starch degradation and carbon partitioning (Appenroth and Gabrys 2003; Keiller and Smith 1989). The blue-light-absorbing phototropins and cryptochromes (CRY), and the red- and far-red-light-absorbing phytochromes (PHY) are the principle families of photoreceptors occurring in higher plants. They direct rapid adaptational changes in gene expression in response to environmental light signals (Monte et al. 2004; Tepperman et al. 2001, 2006), the expression of genes coding for starch enzymes (such as APS1, APL1, SSIV, BAM3, and so on), and nitrogen metabolism (such as NR1) being subjected to PHY-mediated photocontrol (Tepperman et al. 2001). Photoreceptors also direct very rapid cytoplasmic responses (Elzenga et al. 2000; Kinoshita et al. 2001; Rösler et al. 2007; Takagi et al. 2003). Red and far-red light perception by PHY requires the phytochromobilin, which is covalently attached to the PHY apoprotein. In Arabidopsis, this chromophore is synthesized by the products of $H Y 1$ and $H Y 2$ genes (Davis et al. 1999; Kohchi et al. 2001). To investigate the possible involvement of light signaling in MIVOISAP, we compared the FV-promoted increase of starch content between the wild type (WT) and hy2, cry 2 , hyl/cryl, hyl/cry2, and hyl/cryl/cry2. The starch content increase in cry 2 leaves after $16 \mathrm{~h}$ of FV treatment was slightly lower than that of WT leaves (20- to 25 -fold more starch in the presence than in the absence 
of FV) (Fig. 2A), indicating that, independently, CRY does not exert a major effect on MIVOISAP. In clear contrast, an approximately 15 -fold starch content increase occurred in hy2 leaves, and only a 5- to 10-fold starch content increase occurred in hyl/cryl, hyl/cry2, and hyl/cryl/cry 2 mutants after $16 \mathrm{~h}$ of $\mathrm{FV}$ treatment. Thus, the overall data would indicate that MIVOISAP is subjected to the synergic action of both CRY and PHY. We also measured the FV-induced starch content increase in leaves of WT plants cultured under $16 \mathrm{~h}$ of continuous red, far-red, and blue light. These analyses revealed that the FV-induced starch content increase in plants cultured under continuous red light was comparable with that of plants cultured in white light (20- to 25-fold more starch in the presence of FV than in the absence of FV), whereas far-red and blue light promoted an approximately 3-fold increase of the normal starch content (Fig. 2B).

\section{Transcriptome profile of Arabidopsis leaves during MIVOISAP.}

The above results showing that MIVOISAP is subjected to photoreceptor-mediated control would suggest the possibility that MIVOISAP is regulated, at least in part, at the transcriptional level. To test this hypothesis, we carried out time-course analyses of starch content in detached Arabidopsis leaves cultured under white light in solid MS medium in the presence and absence of micromolar concentrations of cordycepin. These analyses revealed that this antibiotic exerted a marked inhibitory effect on starch accumulation after 2 to $3 \mathrm{~h}$ of FV treatment (Fig. 3), which would indicate that MIVOISAP is regulated, at least partially, at the transcriptional level. We then carried out a high-throughput transcriptome analysis of leaves
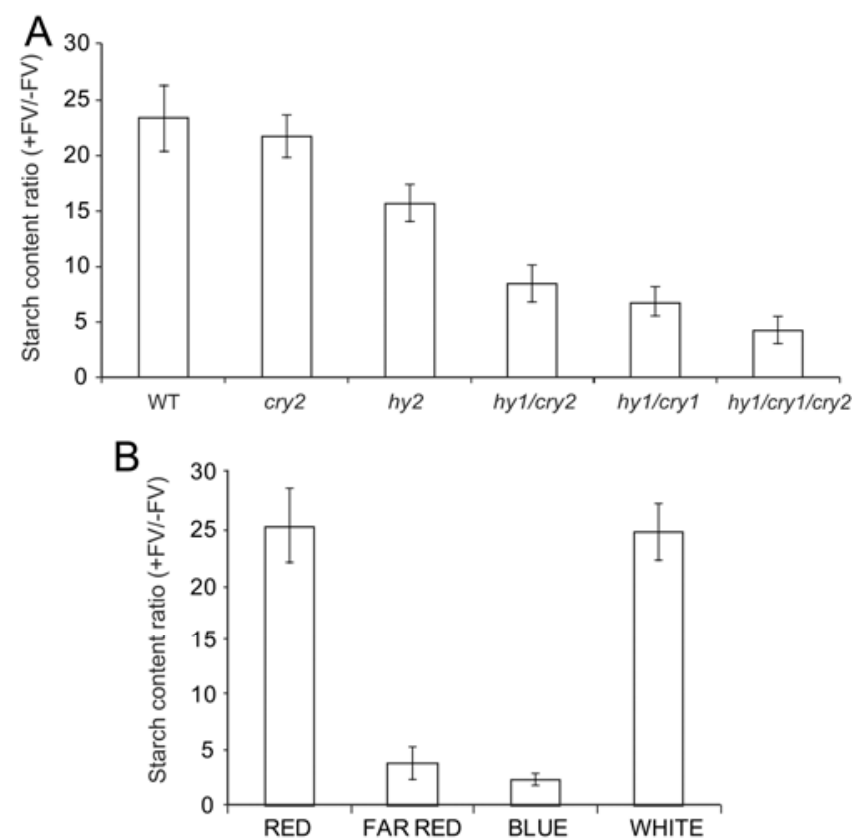

Fig. 2. Arabidopsis is subjected to photoreceptor-mediated control. A, Fungal volatile (FV)-induced increase of starch content in leaves of wild-type (WT), cry2, hy2, hyl/cry1, hyl/cry2, and hyl/cryl/cry2 Arabidopsis plants cultured for $16 \mathrm{~h}$ in solid Murashige-Skoog medium under white light. B, FV-induced increase of starch content in leaves of WT plants cultured under continuous white, red, far-red, and blue light. Graphics represent the ratio between starch content in leaves of FVtreated and nontreated plants. Results are the mean \pm standard error of three independent experiments. Starch content in the leaves of FVnontreated WT plants cultured under white, red, far red, and blue light and of mutants cultured under white light are shown in Supplementary Figure 4. from Arabidopsis plants cultured in MS medium in the absence or in the presence of FV emitted by A. alternata for $16 \mathrm{~h}$ using the Arabidopsis Gene Expression Microarray $4 \times 44 \mathrm{~K}$ (G2519; Agilent Technologies, Santa Clara, CA, U.S.A.). In all, 1,155 genes were found to be deregulated in the presence of FV (more than 1.6-fold difference relative to control; $P$ value $<$ 0.05), 346 of them being annotated as "not function assigned". Among this population, 418 genes were upregulated and 737 genes were downregulated (Supplementary Table 1 for a selected list of genes). Nearly $15 \%$ of the genes whose expression was altered after $16 \mathrm{~h}$ of FV treatment are target genes of SnRK1, a central integrator of transcription networks in plant stress and energy signaling (Baena-González and Sheen 2008; Baena-González et al. 2007), which would suggest that some processes occurring during MIVOISAP are regulated by SnRK1. Quantitative real-time reverse-transcription polymerase chain reaction (RT-PCR) analyses of some of the identified genes (Supplementary Fig. 1) validated the results of the array analyses.

To determine the biological processes affected by microbial volatiles, an analysis of genes using the MapMan tool (Thimm et al. 2004) was carried out. This study revealed that, consistent with our previous studies using potato leaves (Ezquer et al. 2010), FV promoted changes in the expression of Arabidopsis genes involved in multiple processes such as metabolism of carbohydrates, amino acids, and lipids; redox status of the cell; development; cell wall biosynthesis; photosynthesis; secondary metabolism; protein translation and stability; vesicle trafficking; regulation of gene expression; signaling; energy production; plant defense; and stress responses (Fig. 4). No changes were observed in the expression of a number of genes that code for proteins directly or indirectly involved in starch and sucrose metabolism such as plastidial adenylate kinase, plastidial hexokinase, plastidial phosphoglucose isomerase, plastidial phosphoglucomutase, the small and large ADPG pyrophosphorylase (AGP) subunits (APS1 and APL1-4), ADPG pyrophosphatase, sucrose transporters, cytosolic phosphoglucose isomerase, cytosolic phosphoglucomutase, sucrose-phosphate synthase, sucrose-phosphate phosphatase, and invertases. Unlike potato leaves exposed to FV emitted by $A$. alternata (Ezquer et al. 2010), FV treatment did not exert major effects on the expression in leaves of genes coding for Calvin cycle enzymes, plastidial maltose and triose-P/3phosphoglycerate/Pi translocators, alkaline pyrophosphatase, protease inhibitors, soluble SS, starch branching enzyme, plastidial $\beta$-amylases, starch phosphorylases, and plastidial ribosomal proteins.

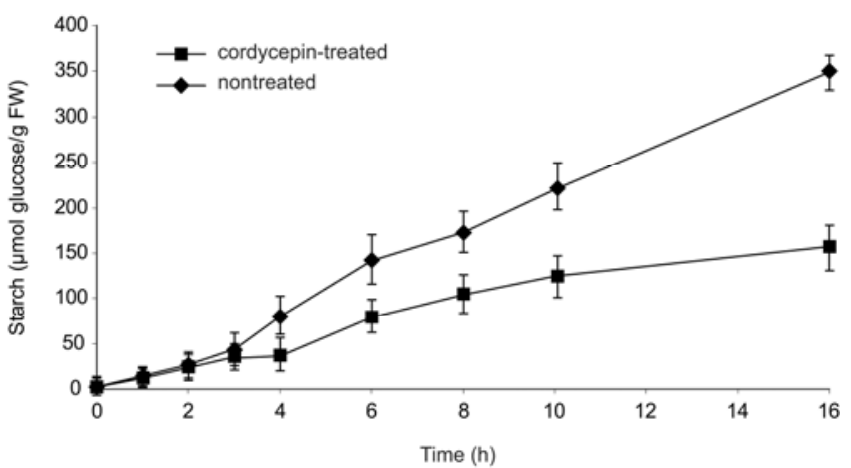

Fig. 3. Time course of starch content in fungal volatile (FV)-treated detached Arabidopsis leaves cultured under white light in solid MurashigeSkoog medium supplemented or not with $30 \mu \mathrm{M}$ cordycepin. Diamonds and squares represent the starch content in leaves cultured in the absence or presence, respectively, of cordycepin. Results are the mean \pm standard error of three independent experiments. 
3-Phosphoglycerate/Pi ratio and levels of reduced AGP form are enhanced during MIVOISAP.

AGP is involved in the production of ADPG linked to starch biosynthesis. This enzyme is allosterically activated by 3phosphoglycerate (3PGA) and inhibited by Pi (Kleczkowski 1999). Allosteric modulation of AGP is considered to represent an important determinant of the starch biosynthesis rate in photosynthetic tissues, although several reports failed to show a correlation between stromal 3PGA levels and starch content (Geigenberger et al. 1996; Westrarm et al. 2002). Time-course analyses of FV-treated and nontreated Arabidopsis leaves revealed that the total 3PGA/Pi ratio increased after $6 \mathrm{~h}$ of FV treatment, which is mainly due to accumulation of 3PGA (Fig. 5). AGP activity is also subjected to redox regulation of the small AGP subunit (APS1) (Hendriks et al. 2003; Kolbe et al. 2005; Michalska et al. 2009). To investigate whether MIVOISAP is accompanied by changes in the redox status of APS1, we carried APS1 immunoblot analyses of proteins from FVtreated and nontreated WT leaves that had previously been extracted and electrophoretically separated under nonreducing conditions. In these conditions, APS1 is present as a mixture of $50-\mathrm{kDa}$ active (reduced) monomers and 100-kDa inactive (oxidized) dimers formed by intermolecular links involving Cys bridges (Hendriks et al. 2003; Kolbe et al. 2005) (discussed below). Consistent with the findings of Hendriks and associates (2003), these analyses revealed that most of APS1 is largely oxidized (inactive) in FV-nontreated leaves (Fig. 6A). Unlike potato leaves (Ezquer et al. 2010), a two- to threefold increase in the relative content of the monomeric APS 1 form was observed when plants were treated with FV, although most of APS1 still remained in the oxidized form (Fig. 6A; Supplementary Fig. 2). Notably, the process of FV-promoted APS1 reduction was rapid (Fig. $6 \mathrm{~B}$ ) and took place in both the presence and absence of light (Fig. 6A).

Western blot analyses of proteins extracted and electrophoretically separated under reducing conditions revealed no apparent difference in APS1 amount between FV-treated and nontreated leaves (Fig. 6C), which is consistent with the transcriptomic analyses showing that MIVOISAP is not accompanied by changes in APS1 expression.

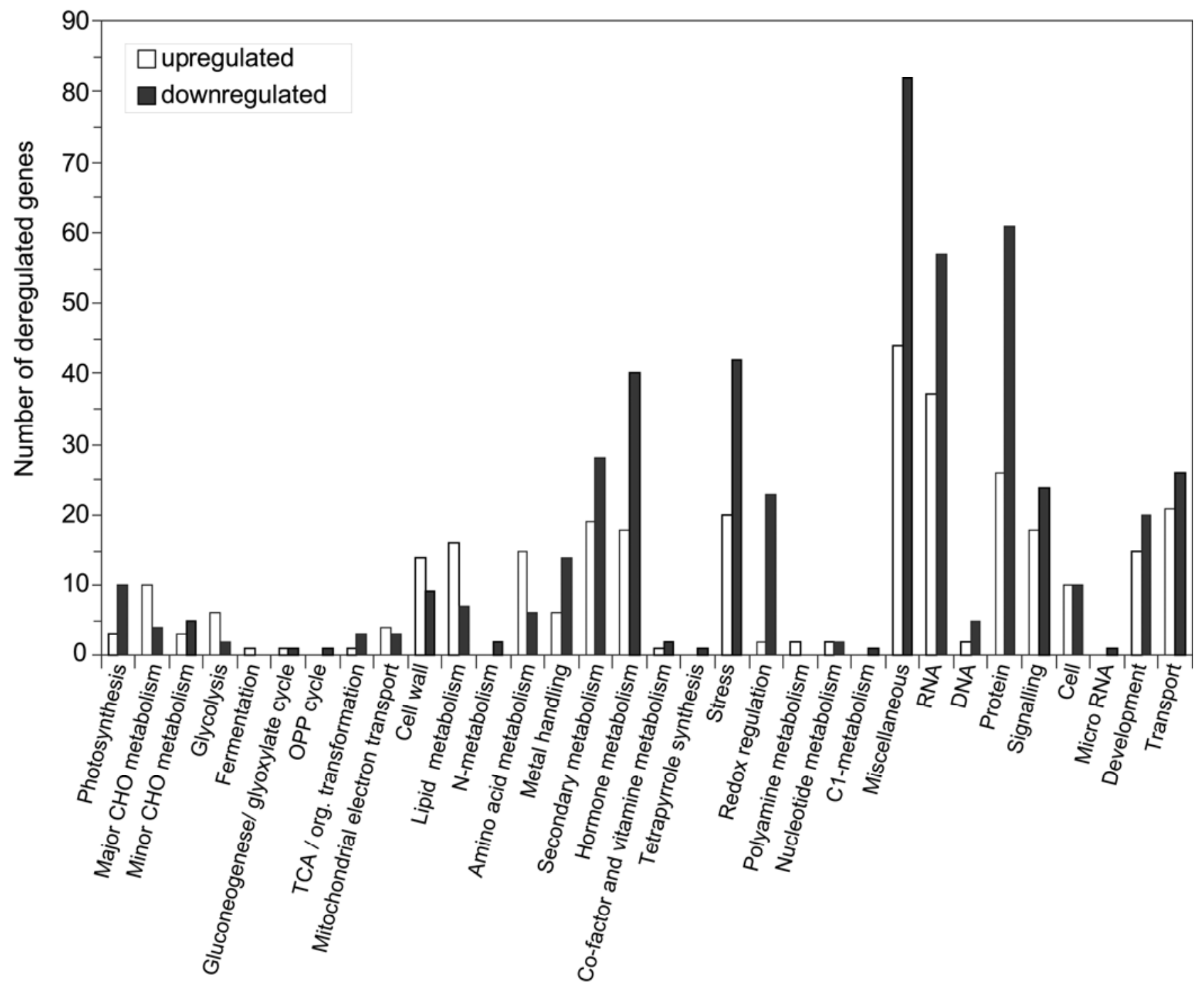

Fig. 4. Functional categorization of the transcripts differentially expressed in leaves of Arabidopsis plants cultured in solid Murashige-Skoog in the presence of fungal volatiles (FV) emitted by Alternaria alternata. Transcripts were identified using the Arabidopsis Gene Expression Microarray $4 \times 44 \mathrm{~K}$ (G2519; Agilent Technologies). Significantly down- and upregulated transcripts (1.6-fold change) as compared with control were sorted by their putative functional category according to the MapMan software. The number of deregulated genes in each categorical group is presented here. Upregulated genes are in white bars and downregulated genes are in black bars. Genes from the "no hits found" category were not included in the graphic. 
NADPH thioredoxin reductase is an important determinant of MIVOISAP.

Regulation of protein function by changes in redox status plays a major role in multiple aspects of plant life such as
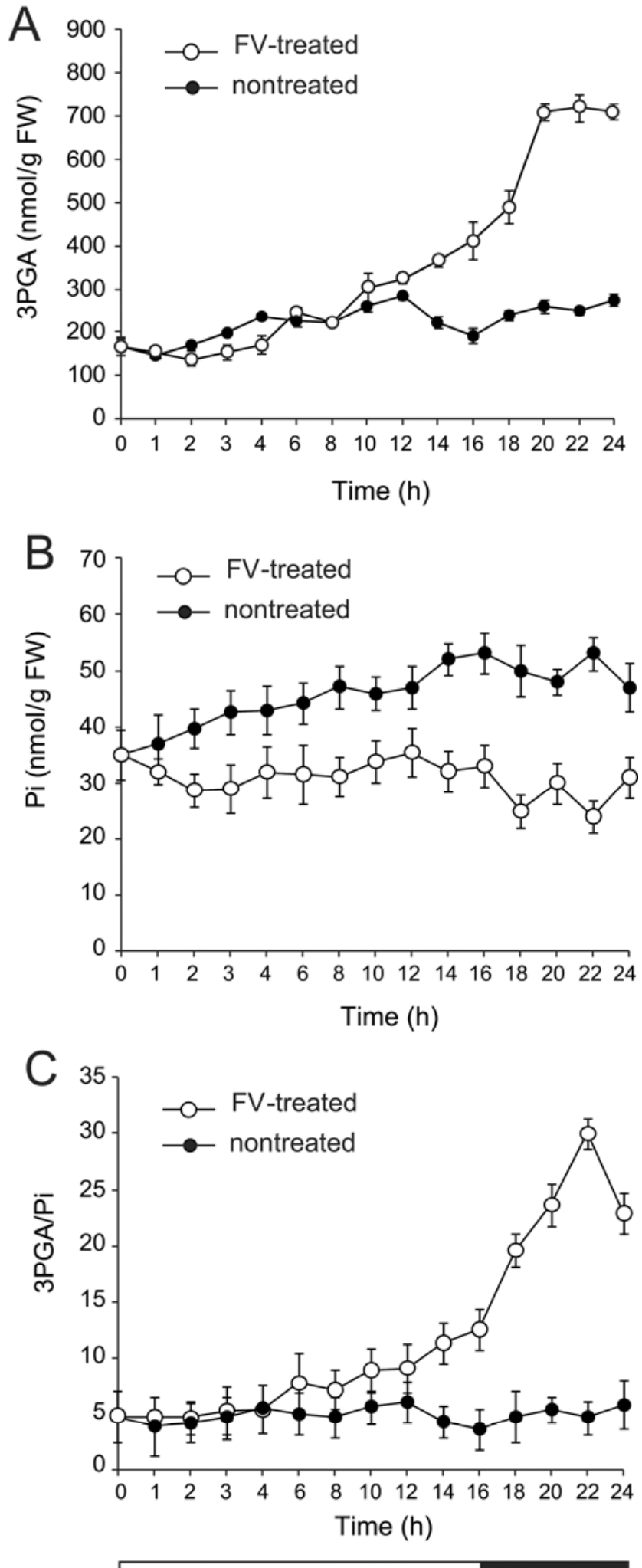

Fig. 5. Time course of A, 3-phosphoglycerate (3PGA); B, Pi; and $\mathbf{C}$, 3PGA/Pi ratio in leaves of fungal volatile $(\mathrm{FV})$-treated $(\mathrm{O})$ and nontreated (-) wild-type Arabidopsis plants for $16 \mathrm{~h}$ of illumination under white light and $8 \mathrm{~h}$ of darkness. Results are the mean \pm standard error of three independent experiments. growth, development, and response to environmental constrains. Illumination results in a very rapid, PHY-mediated activation of proton-pumping plasma membrane ATPases which, in turn, leads to rapid changes of membrane potentials, ion fluxes, and internal cellular redox status (Crane et al. 1991). Illumination also affects the redox status of the photosynthetic electron transport chain in the chloroplast that, in turn, affects the activity of numerous enzymes. Chloroplasts possess two important redox systems that independently regulate plastid metabolism by supplying reducing equivalents to target enzymes. One is based on thioredoxins (Trx) and the other pathway is based on the peculiar NTRC. Whereas the Trx-dependent pathway obtains reducing power from ferre-

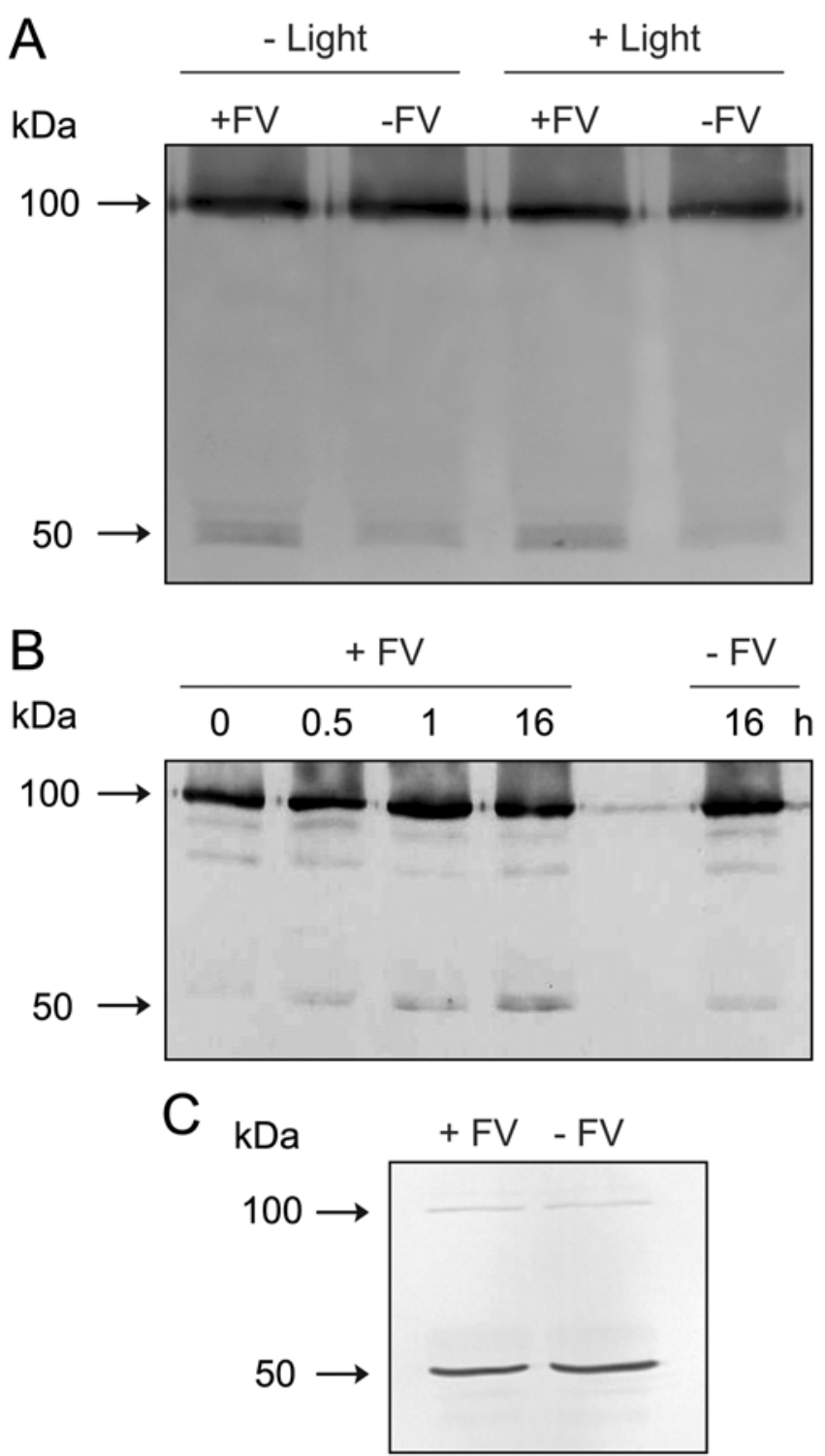

Fig. 6. Western blot analysis of ADP-glucose pyrophosphorylase in fungal volatile (FV)-treated and nontreated wild-type leaves whose proteins were extracted and electrophoretically separated under $\mathbf{A}$ and $\mathbf{B}$, nonreducing conditions and $\mathbf{C}$, reducing conditions. A, Proteins from leaves of illuminated and nonilluminated plants cultured in the presence or absence of FV. Note that, regardless of the presence of light, the relative content of the monomeric (approximately $50 \mathrm{kDa}$ ) form increases when plants were exposed to FV. B, Proteins from nonilluminated leaves and from leaves illuminated for $30 \mathrm{~min}, 1 \mathrm{~h}$, and $16 \mathrm{~h}$ in the presence or absence of FV. A and $\mathbf{C}$, Leaves were harvested after $16 \mathrm{~h}$ of FV treatment; $\mathbf{A}$ and $\mathbf{B}$, proteins coming from $1 \mathrm{mg}$ of FW were loaded per lane; $\mathbf{C}, 20 \mu \mathrm{g}$ of protein was loaded per lane. 
doxin $(\mathrm{Fdx})$ reduced by the photosynthetic electron chain and mediated by Fdx-dependent Trx reductase (FTR) (Lemaire et al. 2007; Meyer et al. 2008), NTRC uses NADPH as the reducing power source, which can be produced in darkness from
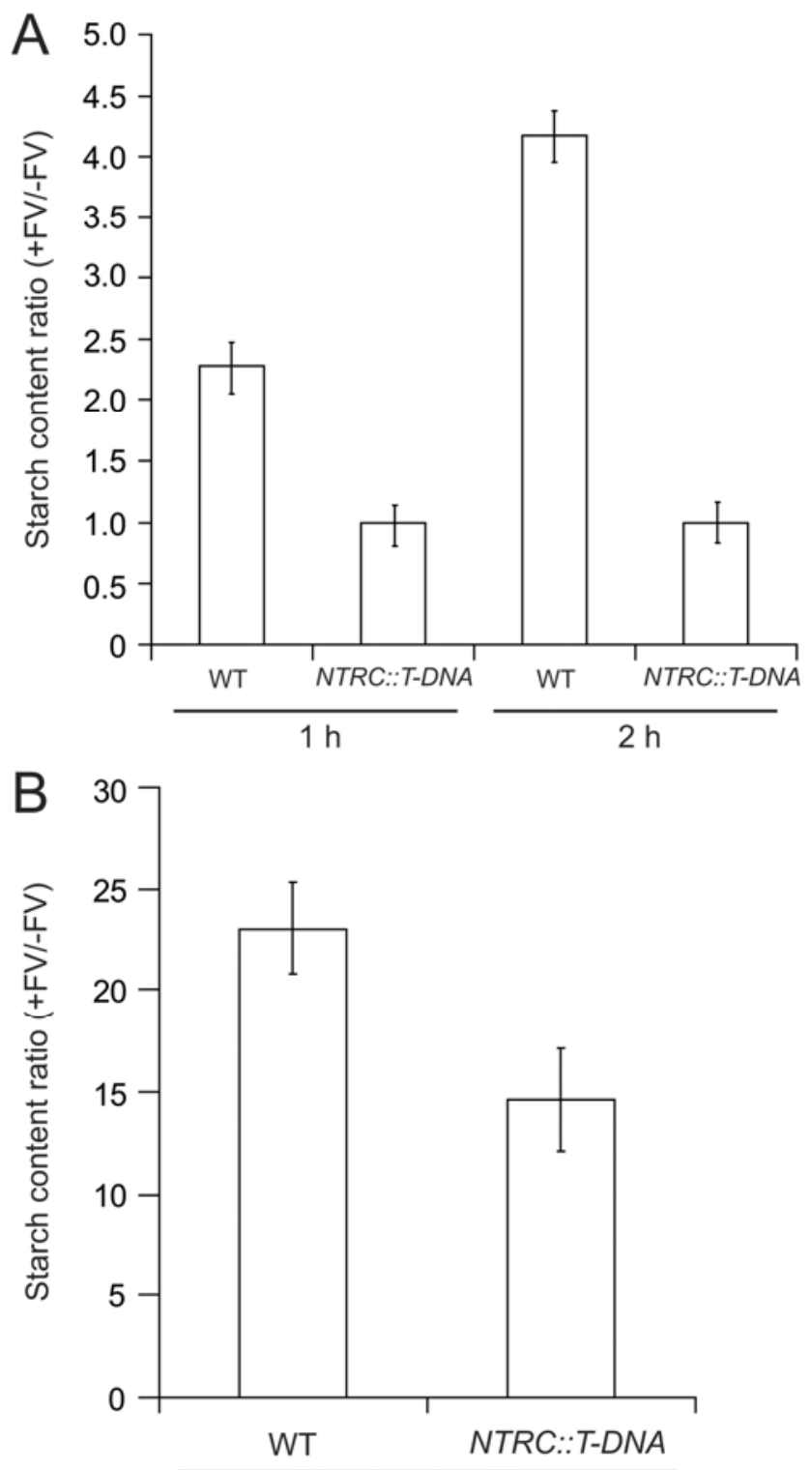

$16 \mathrm{~h}$

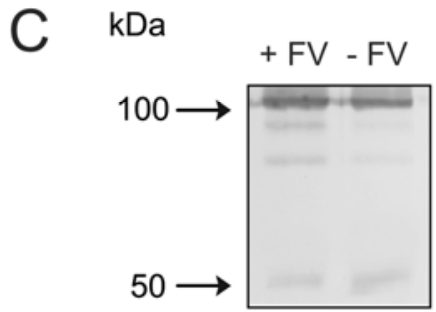

Fig. 7. NADP-thioredoxin reductase $\mathrm{C}$ (NTRC) is involved in microbial volatile-induced starch accumulation process (MIVOISAP). Fungal volatile (FV)-induced increase of starch content in leaves of wild-type (WT) and ntrc mutants cultured for A, 1 and $2 \mathrm{~h}$ and $\mathbf{B}, 16 \mathrm{~h}$ in solid Murashige-Skoog medium under white light. The graphic represents the ratio between starch content in leaves of FV-treated and nontreated plants. Results are the mean \pm standard error of three independent experiments. C, Western blot analysis of ADP-glucose pyrophosphorylase (AGP) in FV-treated and nontreated ntrc leaves whose proteins were extracted and electrophoretically separated under nonreducing conditions. Note that, unlike the case of WT leaves, redox status of AGP was not altered upon $16 \mathrm{~h}$ of exposure to FV.
G6P via the oxidative pentose phosphate pathway (OPPP), or obtained in the light from reduced Fdx via Fdx-NADP reductase (Pérez-Ruiz and Cejudo 2009). Trx may regulate starch metabolism through posttranslational redox changes of enzymes involved in starch breakdown such as SEX1 (Mikkelsen et al. 2005) and BAM1 (Sparla et al. 2006; Valerio et al. 2010). NTRC plays important roles in supplying reductant for detoxifying hydrogen peroxide in the dark and in regulating the redox status of AGP (Michalska et al. 2009; Pulido et al. 2010) (discussed above).

One of the most striking alterations in the transcriptome of Arabidopsis leaves treated with FV emitted by A. alternata involves the activation of plasma-membrane-type proton ATPases, as well as repression of plastidial FTR and various Trx. The former would result in changes of membrane potentials, ion fluxes, and internal cellular redox status. The latter would result in a partial blockage of the main link between light absorbed by chlorophylls and metabolic activity in the plastid (the Fdx/Trx system) which, in turn, would favor the NTRC pathway as an alternate system for transferring reducing equivalents to target enzymes. Whether plastidial Trx and NTRC play a role in Arabidopsis MIVOISAP was examined by measuring the starch content in ntrc and the plastidial Trx $\mathrm{f} 1, \mathrm{f} 2, \mathrm{y} 1, \mathrm{~m} 2$, and $\mathrm{m} 3$ mutants cultured in the absence or presence of FV for $16 \mathrm{~h}$. These analyses revealed that the FVinduced increase of starch content in the plastidial Trx mutants was comparable with that of WT plants (20- to 25-fold more starch in the presence than in the absence of FV). Notably, FV did not promote starch accumulation in the leaves of ntrc mutants during the first $2 \mathrm{~h}$ of FV treatment (Fig. 7A), and only an approximately 15 -fold increase of starch content occurred in the leaves of ntrc mutants after $16 \mathrm{~h}$ of FV treatment (Fig. 7B). Thus, the overall data strongly indicated that, i) independently, $\operatorname{Trx} \mathrm{f} 1, \mathrm{f} 2, \mathrm{y} 1, \mathrm{~m} 2$, and $\mathrm{m} 3$ do not exert a major control on MIVOISAP; and ii) NTRC is an important determinant of Arabidopsis MIVOISAP, especially during the initial $2 \mathrm{~h}$ of FV treatment. The fact that FV do not promote starch accumulation in ntrc mutants during the initial $2 \mathrm{~h}$ of treatment is consistent with the idea that NTRC regulates MIVOISAP at the post-translational level.

Recent studies have shown that NTRC adjusts the redox status of several target proteins involved in different metabolic or signaling pathways (Pulido et al. 2010). Results strongly indicated that FV promote partial AGP reduction (Fig. 6). To investigate whether this phenomenon is mediated by NTRC, AGP Western blot analyses of FV-treated and nontreated ntrc mutants were carried out under nonreducing conditions. These analyses revealed that, unlike WT leaves (Fig. 6A), no changes in the redox status of AGP occurred when ntrc mutants were exposed to FV (Fig. 7C), the overall data indicating that FVpromoted AGP reduction is exclusively mediated by NTRC.

\section{SS classes III and IV are major determinants of Arabidopsis MIVOISAP.}

Five distinct classes of SS are known in plants: granulebound SS (GBSS), which is responsible for the synthesis of amylose; and soluble SS classes I, II, III, and IV (SSI, SSII, SSIII, and SSIV, respectively), which are responsible for the synthesis of amylopectin. Roldán and associates (2007) demonstrated that elimination of SSIV resulted in the accumulation of only one large starch granule in Arabidopsis chloroplasts. Furthermore, using different combinations of SS mutations in SSIII and SSIV mutant backgrounds, Szydlowski and associates (2009) have recently shown that autotrophically grown Arabidopsis SSIII/SSIV double mutants accumulated null starch levels, whereas SSI/SSII/SSIII triple T-DNA mutants accumulated nearly $20 \%$ of the WT starch levels. Their data i) 
indicated that both SSIII and SSIV play a key role in starch accumulation, although SSIV is mandatory to render the regular number of starch granule found in WT plants; and ii) suggested that SSIV plays a crucial role in the starch granule initiation process.

Our transcriptome analyses of leaves of FV-treated Arabidopsis plants revealed no changes in the expression of SSI, SSII, SSIII, SSIV, and GBSS, showing that changes in SS-encoding gene expression play a minor role, if any, in Arabidopsis MIVOISAP. Whether SS are involved in MIVOISAP was investigated by measuring starch content in leaves of homozygous GBSS, SSI, SSII, SSIII, SSIV, SSI/SSIV, SSII/SSIV, SSIII/SSIV, SSI/SSII/SSIII, and SSI/SSII/SSIV T-DNA mutants cultured, for $16 \mathrm{~h}$, in the presence or in the absence of FV emitted by A. alternata. These analyses revealed that the FVinduced increase of starch content in leaves of GBSS, SSI, and SSII T-DNA mutants was normal when compared with WT leaves (20- to 25 -fold more starch in the presence than in the absence of FV). In clear contrast, the increase of leaf starch content in FV-treated SSIII, SSIV, SSI/SSIV, SSII/SSIV, and SSI/SSII/SSIV T-DNA mutants was markedly lower than in FVtreated WT leaves (Fig. 8). Furthermore, FV treatment did not promote starch accumulation in SSIII/SSIV and SSI/SSII/SSIII T-DNA mutants. Thus, the overall data indicated that SSIII and SSIV are important determinants of Arabidopsis MIVOISAP. Taking into account that SSIII and SSIV expression levels do not change upon FV treatment, it is inferred that, similar to AGP (Fig. 6), both enzymes are in excess and largely inactive in FV-nontreated plants. Furthermore, the results indicate that SSIII and SSIV are activated after FV treatment by yet-to-beidentified post-translational mechanisms.

\section{Fungal volatiles promote decay of amino acid biosynthesis in Arabidopsis leaves.}

Starch and glycogen are the main storage carbohydrates in plants and bacteria, respectively, their metabolism being tightly connected with that of nitrogen (amino acid) by still poorly understood mechanisms. In plants, nitrate represses starch metabolism in leaves (Scheible et al. 1997). In bacteria, a decreased demand in ATP-dependent protein synthesis and breakdown takes place under conditions of limited amino acid provision, with excess ATP and carbon being diverted from protein metabolism toward glycogen biosynthesis (Eydallin et al. 2007; Montero et al. 2009; Wilson et al. 2010).

Leaves of Arabidopsis plants exposed to FV accumulated markedly reduced levels of Gly $(1.15 \pm 0.19 \mu \mathrm{mol} / \mathrm{g} \mathrm{FW}$ in the absence of FV versus $0.52 \pm 0.08 \mu \mathrm{mol} / \mathrm{g} \mathrm{FW}$ in the presence of FV) and $\mathrm{Arg}(1.35 \pm 0.2 \mu \mathrm{mol} / \mathrm{g} \mathrm{FW}$ in the absence of FV versus $0.58 \pm 0.15 \mu \mathrm{mol} / \mathrm{g} \mathrm{FW}$ in the presence of $\mathrm{FV}$ ), and moderately reduced levels of Ser $(2.62 \pm 0.23 \mu \mathrm{mol} / \mathrm{g}$ FW in the absence of FV versus $2.13 \pm 0.10 \mu \mathrm{mol} / \mathrm{g} \mathrm{FW}$ in the presence of FV). MIVOISAP was also accompanied by a marked increase of Pro $(2.20 \pm 0.27 \mu \mathrm{mol} / \mathrm{g} \mathrm{FW}$ in the absence of FV versus $3.63 \pm 0.39 \mu \mathrm{mol} / \mathrm{g} \mathrm{FW}$ in the presence of $\mathrm{FV}$ ), an amino acid accumulating in response to environmental stress that plays important roles in stabilizing the redox balance and energy status of the cell (Szabados and Savouré 2009). Nitrate reductase (NR) is a cytosolic enzyme playing a key role in nitrate assimilation and amino acid biosynthesis. It is highly regulated, being inactivated by SnRK1-mediated phosphorylation (Kaiser and Huber 2001; Lillo et al. 2004). Quantitative RT-PCR and array analyses revealed that, similar to potato leaves (Ezquer et al. 2010), Arabidopsis MIVOISAP is accompanied by downregulation of $N R I$ expression (2.44-fold reduction) which, in turn, was accompanied by a concomitant reduction of NR activity $(100.8 \pm 8.3 \mathrm{mU} / \mathrm{g} \mathrm{FW}$ and $59 \pm 3.35 \mathrm{mU} / \mathrm{g}$ FW in the absence and presence of FV, respectively). These observations prompted the hypothesis that, similar to bacteria, a decreased demand of ATP and carbon occurring during impairment in internal amino acid provision would result in starch overaccumulation. To investigate this possibility, we measured the starch content in detached Arabidopsis leaves cultured in the presence and in the absence of FV emitted by A. alternata, and in the presence of different amino acids. Most notably, these analyses revealed that, similar to potato leaves (Ezquer et al. 2010), MIVOISAP was strongly repressed by exogenously added Cys whereas other amino acids such as Ser and Gly did not exert a negative effect on MIVOISAP (Fig. 9). We also measured the starch content in leaves of $N R 1: \because T-D N A$ mutants and in leaves of $O A S-A I$ and $O A S-B$ T-DNA mutants impaired in cytosolic and plastidial Cys biosynthesis, respectively (Bermúdez et al. 2010). These analyses revealed that these mutants accumulated nearly WT starch content in both the presence and absence of FV (Supplementary Figs. 3 and 4). Thus, the overall data would indicate that, whereas MIVOISAP appears to be the consequence, at least in part, of inadequate internal Cys provision, changes in the expression or action of $N R 1, O A S$ - $A 1$, and $O A S$-B do not independently exert a major effect on MIVOISAP.

\section{Trehalose and trehalose-6-phosphate are not involved in Arabidopsis MIVOISAP.}

Trehalose is a disaccharide that occurs both in a large variety of microorganisms and, in trace amounts, in plants. Its precursor, trehalose-6-P (T6P), is indispensable for the regulation of growth and starch biosynthesis (Kolbe et al. 2005; Lunn et al. 2006). Altering trehalose metabolism results in dramatic pleiotropic effects, such as morphological changes, growth defects, and altered carbon metabolism (Schluepmann et al. 2003). External application of trehalose for 10 days exerts dramatic effects on both growth and starch metabolism in Arabidopsis plants, severely curtailing root and shoot growth, and causing starch overaccumulation in cotyledons and leaves (Fritzius et al. 2001; Ramon et al. 2007; Wingler et al. 2000). This phenomenon is accompanied by an increase of APL3 expression and reduction of the expression levels of genes involved in starch breakdown such as SEX1 and BAM3. Schluepmann and associates (2004) have proposed that T6P rather than trehalose causes the observed effects on carbon metabolism. A positive effect exerted

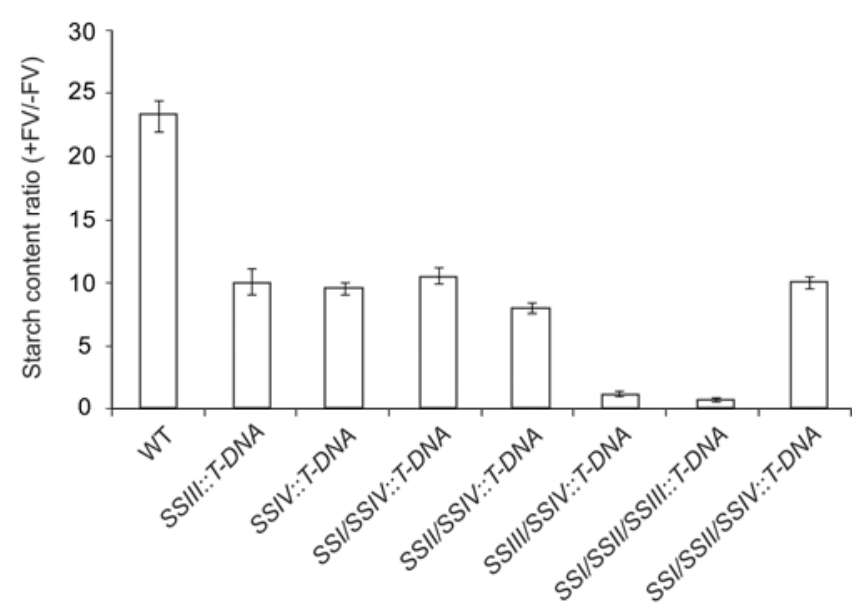

Fig. 8. Fungal volatile (FV)-induced increase of starch content in leaves of wild-type plants and starch synthase (SS) class SSIII, SSIV, SSI/SSIV, SSII/SSIV, SSIII/SSIV, SSI/SSII/SSIV, and SSI/SSII/SSIII T-DNA mutants cultured for $16 \mathrm{~h}$ in solid Murashige-Skoog medium under white light. The graphic represents the ratio between starch content in leaves of FV-treated and nontreated plants. Results are the mean \pm standard error of three independent experiments. 
by T6P on starch accumulation has been ascribed to its effect on the plastidial Trx-mediated posttranslational redox activation of AGP (Kolbe et al. 2005). We investigated whether changes in trehalose metabolism play a major role in MIVOISAP by measuring starch content in FV-treated and nontreated Arabidopsis plants cultured for $16 \mathrm{~h}$ under white light in solid MS medium supplemented with either $30 \mathrm{mM}$ trehalose or sucrose. Furthermore, we measured the starch content in FV-treated and nontreated detached Arabidopsis leaves cultured directly in contact with solid MS medium supplemented with either $30 \mathrm{mM}$ trehalose or sucrose. These analyses revealed that starch levels in both FV-nontreated detached leaves and leaves of plants cultured for $16 \mathrm{~h}$ in MS supplemented with trehalose were comparable with or even lower than those of FV-nontreated detached leaves and leaves of plants cultured in MS sucrose (Fig. 10), indicating that trehalose or T6P metabolism is not involved in MIVOISAP.

Trehalose biosynthesis involves a two-step process catalyzed by T6P synthase (TPS) and T6P phosphatase (TPP). Of the 11 annotated Arabidopsis TPS genes, our transcriptomic analyses revealed that TPS5 expression was upregulated (2.10-fold increase), whereas TPS8, TPS9, and TPS11 expression was downregulated (2.01-, 1.63-, and 1.98-fold reduction, respectively) when plants were cultured in the presence of FV emitted by $A$. alternata. We measured the starch content in homozygous TPS1, TPS5, TPS9, and TPS11 T-DNA mutants cultured in the presence or absence of FV. The FV-induced increase of starch content in these mutants was comparable with that of WT plants (20- to 25-fold increase upon FV treatment). Thus, the overall data would further indicate that changes in trehalose metabolism play a minor role, if any, in MIVOISAP.

\section{Plastidial $\beta$-amylase-mediated starch breakdown is activated during MIVOISAP.}

Of the nine $\beta$-amylase-like proteins encoded in the Arabidopsis genome (BAM1 to BAM9), only BAM1 to BAM4 are plastidial and, thus, have direct access to starch (Fulton et al. 2008; Lao et al. 1999; Sparla et al. 2006). BAM1 degrades starch during the day in both mesophyll and in guard cells subjected to heat shock and osmotic stress (Kaplan and Guy 2004; Valerio et al. 2010). BAM3 is a major determinant of leaf starch degradation during the night (Fulton et al. 2008), also playing an important role in starch degradation during the day upon cold shock (Kaplan and Guy 2005). BAM4 is a noncatalytic protein required for starch breakdown, acting upstream of BAM1 to BAM3 (Fulton et al. 2008). Unlike plastidial $\beta$-amylases, the precise roles of extraplastidial $\beta$-amylases and the plastidial $\alpha$-amylase AMY3 in starch metabolism are still unknown. Although Laby and associates (2001) showed that mutants impaired in BAM5 accumulate normal starch levels, more recent studies have shown that bam5 mutants can display a starch-excess phenotype (Kaplan and Guy 2005). Furthermore, although $\mathrm{Yu}$ and associates (2005) provided evidence that AMY3 is not required for transitory starch breakdown, Kaplan and Guy (2005) showed that amy3 mutants accumulate more starch than WT leaves.

Isoamylase 3 (ISA3) is a debranching enzyme that participates in $\beta$-amylolytic starch degradation by releasing maltodextrins into the stroma (Wattebled et al. 2005). Our transcriptome analyses revealed that FV promote the expression of ISA3 (1.72-fold increase). These analyses also revealed a marked increase of $B A M 5$ expression upon FV treatment (4.81-fold increase), which was accompanied by a 3.1-fold increase of the total $\beta$-amylase activity $(11.8 \pm 2.1$ and $37.0 \pm$ $3.2 \mathrm{U} / \mathrm{g} \mathrm{FW}$ in the absence and presence, respectively, of FV for $16 \mathrm{~h}$ ). Therefore, FV-induced enhancement of total $\beta$-amylase activity can be ascribed to upregulation of BAM5. Whether plastidial amylases or BAM5 are major determinants of MIVOISAP was investigated by measuring the starch content in leaves of FV-treated and nontreated homozygous $B A M 4$, $B A M 5$, and $A M Y 3$ T-DNA mutants cultured for $16 \mathrm{~h}$ under white light. We also measured the starch content in sex $1 \mathrm{mu}-$ tants lacking a plastidial $\alpha$-glucan, water dikinase that catalyzes the phosphorylation of starch necessary for normal $\beta$-amylasedependent starch breakdown (Edner et al. 2007). FV-nontreated bam 5 and amy 3 leaves accumulated WT starch content, whereas FV-nontreated bam4 and sexl leaves accumulated approximately fivefold more starch than WT leaves (Fig. 11A). Unlike amy3 and bam5 leaves accumulating WT starch levels upon 16 $\mathrm{h}$ of FV treatment (20- to 25 -fold more starch in the presence than in the absence of FV), FV-treated sexl and bam4 leaves accumulated approximately 30 -fold more starch than WT leaves (Fig. 11A), suggesting the possible occurrence of plastidial $\beta$ amylase-mediated starch breakdown during MIVOISAP. To in-

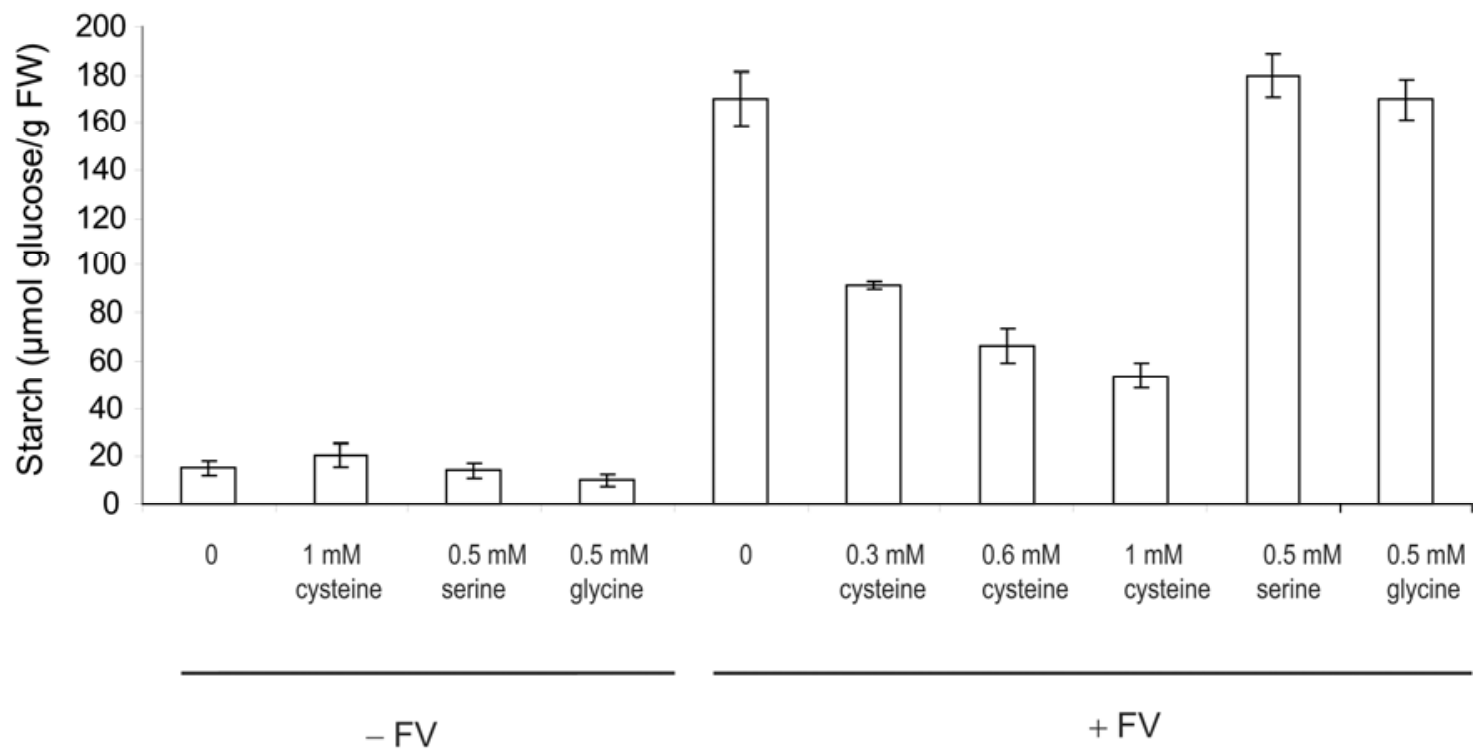

Fig. 9. Microbial volatile-induced starch accumulation process is strongly repressed by exogenously added Cys. Fungal volatile (FV)-treated and nontreated detached Arabidopsis leaves were cultured in solid Murashige-Skoog supplemented with the indicated concentrations of amino acids. After 16 h of culture, leaves were harvested and starch content was measured. Results are the mean \pm standard error of three independent experiments. 
vestigate this hypothesis, we measured the content of maltose (the product of the $\beta$-amylase reaction) in WT and BAM4 TDNA mutants cultured in the presence and absence of FV. Notably, these analyses revealed that maltose rapidly accumulated after $2 \mathrm{~h}$ of FV treatment in WT leaves and, to a much lesser extent, in bam4 leaves (Fig. 11B). Thus, the overall data strongly indicated that i) plastidial $\beta$-amylase-dependent starch degradation is rapidly activated upon FV treatment and ii) starch biosynthesis and breakdown simultaneously occur during MIVOISAP. Because expression levels of plastidial $\beta$ amylases do not change upon FV treatment, it is inferred that plastidial $\beta$-amylase is in excess and largely inactive in FVnontreated plants, and activated after FV treatment by as-yetto-be-identified post-translational mechanisms.

\section{Additional remarks and proposal of an integrative model of starch metabolism during MIVOISAP.}

Plants have evolved multiple defense mechanisms against microbial pathogens. Contact with microorganisms or elicitors very often leads to very rapid activation of ion fluxes, phos-
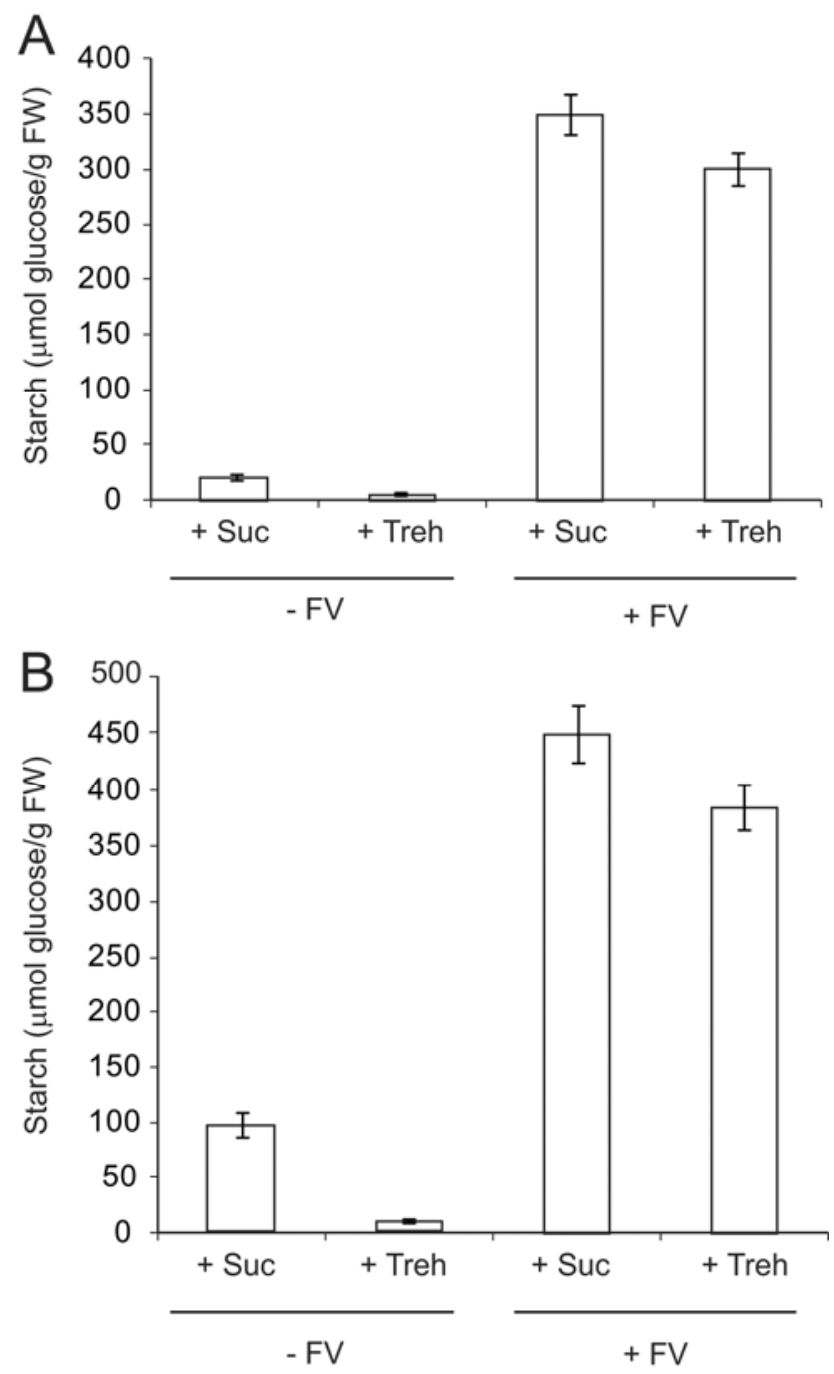

Fig. 10. Trehalose is not a major determinant of the microbial volatileinduced starch accumulation process. A, Starch content in leaves of fungal volatile (FV)-treated and nontreated wild-type Arabidopsis plants cultured for $16 \mathrm{~h}$ in solid Murashige-Skoog (MS) supplemented with $30 \mathrm{mM}$ sucrose or $30 \mathrm{mM}$ trehalose. B, Starch content in FV-treated and nontreated detached Arabidopsis leaves cultured for $16 \mathrm{~h}$ directly in contact with solid MS supplemented with $30 \mathrm{mM}$ sucrose or $30 \mathrm{mM}$ trehalose. Results are the mean \pm standard error of three independent experiments. phorylation or dephosphorylation of proteins, and production of signaling molecules that lead to the regulation of gene expression and the induction of defense responses, including production and accumulation of secondary metabolites and transition from source to sink status in photosynthetic tissues (Berger et al. 2007). Indications of the induction to a sink status in infected leaves are the upregulation of SuSy (Eckey et al. 2004; Michel et al. 2006), which may serve to allocate sucrose into callose deposition and to promote cell wall polysaccharide biosynthesis at infection sites (Essmann et al. 2008), although a recent report has provided evidence that $\mathrm{SuSy}$ is not required for cell wall biosynthesis in Arabidopsis (Barratt et al. 2009). Furthermore, contact with microorganisms or elicitors may also result in downregulation of primary $\mathrm{N}$-assimilation genes such as NR (Pageau et al. 2006) and in the activation of starch breakdown enzymes that facilitate the availability of simple sugars for the microbes at infection sites. Consistently, in this work we have observed that microbial volatile-induced accumulation of exceptionally high levels of starch is accompanied by activation of starch breakdown pathways (Fig. 11) and downregulation of NR in Arabidopsis. Microarray analyses also revealed that FV treatment resulted in enhanced SUS1 expression (1.69-fold increase), which was accompanied by a concomitant increase of SuSy activity (182.5 \pm 18.3 and $280 \pm$ $24 \mathrm{mU} / \mathrm{g} \mathrm{FW}$ in the absence and presence of FV, respectively).
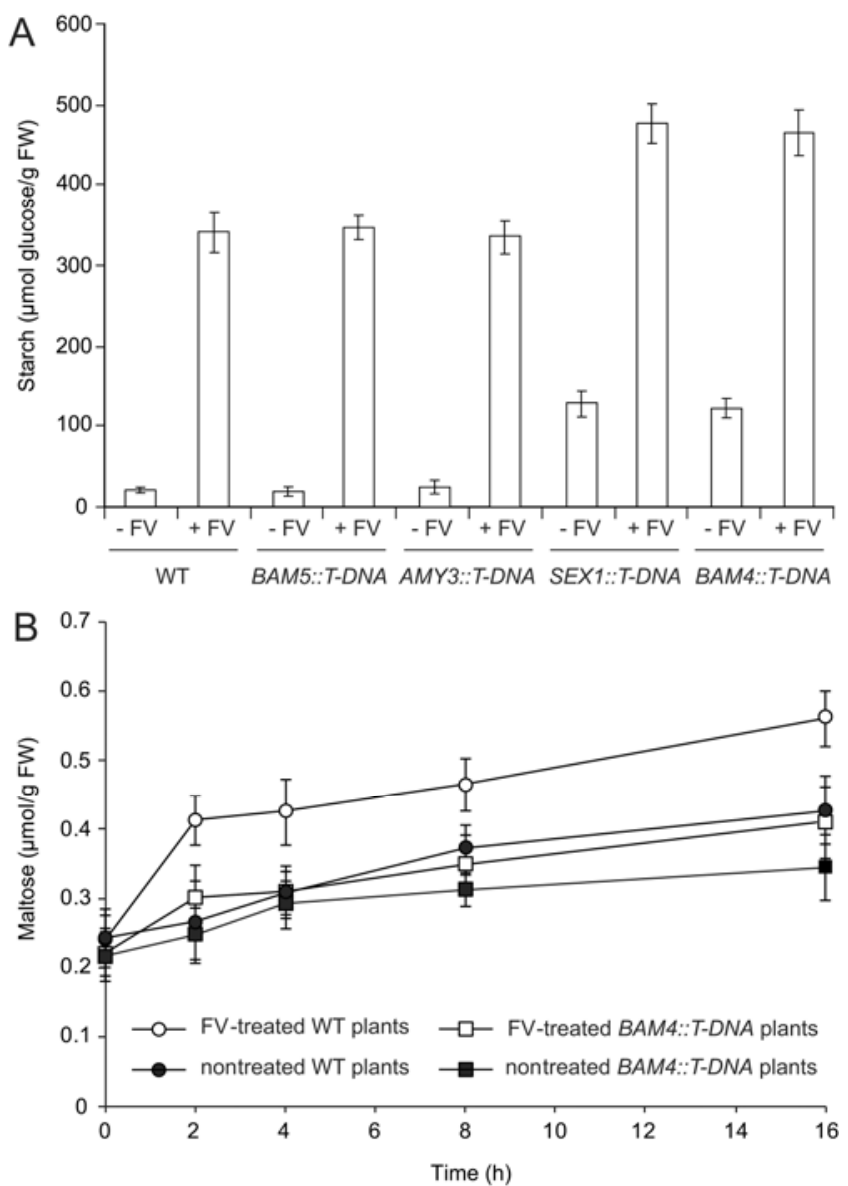

Fig. 11. Plastidial $\beta$-amylase-mediated starch breakdown is activated during the microbial volatile-induced starch accumulation process. A, Starch content in leaves of fungal volatile (FV)-treated and nontreated wild-type (WT), SEX1, BAM4, BAM5, and AMY3 T-DNA Arabidopsis mutants after $16 \mathrm{~h}$ of illumination under white light. B, Time course of maltose content in FV-treated and nontreated WT plants ( $\bigcirc$ and $\bigcirc$, respectively) and BAM4 ( $\square$ and $\square$, respectively) T-DNA mutants. Results are the mean \pm standard error of three independent experiments. 
It has been previously shown that, despite marked changes in their transcript levels, the amount of starch enzymes in Arabidopsis leaves does not change appreciably through the diurnal cycle, which can be ascribed to the occurrence of active protein turnover (Lu et al. 2005; Smith et al. 2004). This showed that day-length and circadian control of starch biosynthesis is exerted primarily through modulation of enzyme activity, and indicated the importance of post-transcriptional control in regulating starch metabolism. In this work, we have provided evidence that, as schematically illustrated in Figure 12, FV-induced accumulation of exceptionally high levels of starch would involve both transcriptional and post-translational regulation of enzymes directly or indirectly related to starch metabolism. Unlike potato leaves, where FV alter the expression of a number of starch- related genes (Ezquer et al. 2010), FV treatment affected the expression of few genes directly involved in starch metabolism in Arabidopsis, indicating that transcriptional control of MIVOISAP would be indirect. Thus, downregulation of $N R I$ expression occurring upon FV treatment would result in a decreased demand of ATP and carbon for amino acid biosynthesis, with excess ATP and carbon being diverted toward starch biosynthesis. Also, upregulation of SuSy may partially contribute to increase the production of ADPG linked to starch biosynthesis (Bahaji et al. 2011; Muñoz et al. 2005).

Results of Figure 1 showing sudden starch accumulation upon FV treatment strongly indicated the occurrence of rapid signaling that, as judged from the results shown in Figures 2, 6 , and 7, would involve photoreceptor- and plastidial Fdx/Trx/

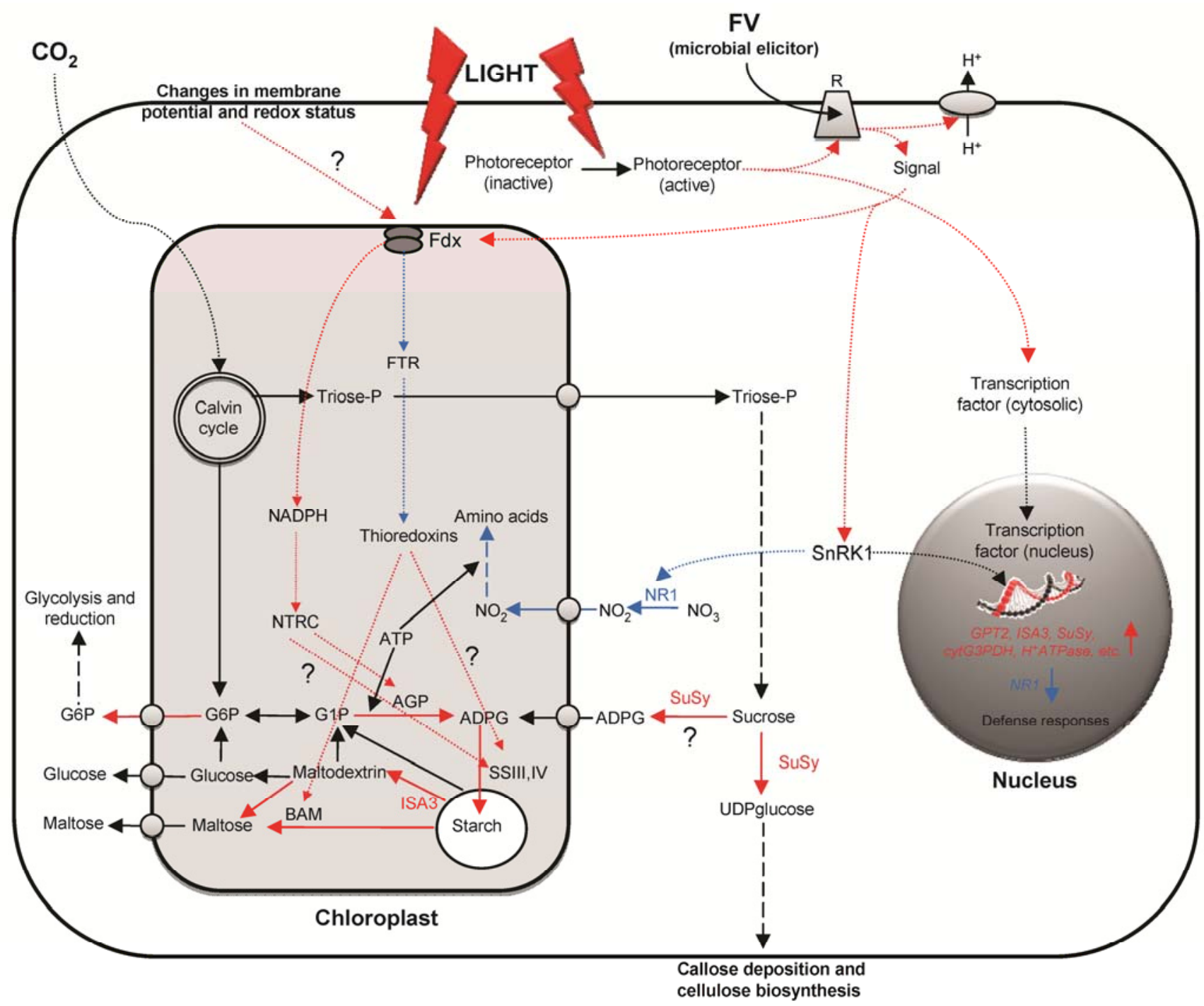

Fig. 12. Suggested model for microbial volatile-induced starch accumulation process (MIVOISAP) in Arabidopsis leaves involving a photocontrolled, transcriptionally and post-translationally regulated network wherein photoreceptors, starch synthase (SS) class SSIII and SSIV, and NADP-thioredoxin reductase $\mathrm{C}$ (NTRC)-mediated changes in redox status of plastidial enzymes play important roles in the conversion of $\mathrm{CO}_{2}$ (both atmospheric and produced by the microorganism) into starch. Light activates photoreceptors, which interact with as-yet-to-be-identified plasma membrane fungal volatile (FV) receptors to produce signaling molecules that rapidly promote i) ferredoxin (Fdx)-, thioredoxin (Trx)-, and NTRC-mediated reduction of plastidial enzymes involved in starch metabolism; ii) proton ATPase-mediated changes in the plasma membrane potential; and iii) activation of SnRK1 (a central integrator of transcription networks in plant stress and energy signaling), thus altering the expression of genes involved in plant defense and carbon metabolism. Reduction of nitrate reductase (NR) activity as a consequence of SnRK1-mediated inhibition of NR and downregulation of NR expression promote decay of plastidial amino acid biosynthesis, the resulting excess ATP and carbon being channeled towards starch biosynthesis. Upregulation of proton-ATPase-encoding genes further contributes to maintain changes in plasma membrane redox status that, in turn, promote Fdx-, Trx-, and NTRC-mediated changes in the redox status of plastidial enzymes. Enhancement of sucrose synthase (SuSy) activity would promote the production of ADP-glucose (ADPG) and UDPglucose linked to the synthesis of starch and cell wall components, respectively. FV treatment promotes isoamylase 3 (ISA3) expression which, together with plastidial $\beta$-amylase, catalyzes starch breakdown. Starch breakdown products (maltose and G6P) are then transported to the cytosol by means of MEX1 and GPT2 (maltose and G6P/Pi transporters, respectively). Red and blue arrows indicate up- and downregulated functions, respectively, during MIVOISAP. 
NTRC-mediated changes in the redox status of enzymes directly or indirectly involved in starch metabolism such as AGP (Fig. 12). Photoreceptors direct rapid activation of plasma membrane proton ATPases in response to light which, in turn, leads to rapid changes of membrane potentials, ion fluxes, redox status, and cytosolic metabolism that would likely favor accumulation of exceptionally high starch levels by as-yet-to-beidentified signals. Notably, FV treatment enhances the expression of various plasma membrane proton ATPases, which would guarantee long-term membrane potentials favoring starch overaccumulation. We must emphasize that previous studies have provided evidence that cytosolic sugars such as trehalose or T6P can act as signaling molecules that affect starch metabolism through regulation of AGP redox status (Geigenberger et al. 2005; Lunn et al. 2006). However, the fact that i) trehalose treatment for $16 \mathrm{~h}$ does not promote starch overaccumulation (Fig. 10), and ii) various tps mutants display normal MIVOISAP tend to indicate that i) trehalose or T6P are not signaling molecules involved in MIVOISAP and ii) FVpromoted changes in AGP redox status shown in Figure 6 are not ascribed to changes in trehalose metabolism. Further studies will be necessary to identify the signals connecting photoreceptor-mediated FV sensing with Fdx/NTRC-mediated reduction and activation of starch enzymes.

Stimulation of $\beta$-amylase-mediated starch degradation in leaves under stress is necessary to both directly support respiration and protect cell structures by raising the levels of maltose as an osmoprotectant (Kaplan and Guy 2004; Valerio et al. 2010). Consistently, results presented in Figure 11 showing FV-promoted maltose accumulation in illuminated WT leaves clearly indicated that plastidial $\beta$-amylase-dependent starch degradation is activated during MIVOISAP. Therefore, MIVOISAP involves simultaneous synthesis and breakdown of starch that may entail advantages such as rapid metabolic channeling toward various pathways in response to physiological and biochemical needs. Because expression levels of plastidial $\beta$-amylases do not change upon FV treatment, it is inferred that these enzymes are in excess and largely inactive in FV-nontreated plants, and activated after FV treatment by as-yet-to-be-identified post-translational mechanisms. A striking alteration in the transcriptome of FV-treated Arabidopsis leaves involves the upregulation of a gene, GPT2, encoding a plastidial G6P/Pi translocator (Kammerer et al. 1998; Kang and Rawsthorne 1996) (8.76-fold increase). Similar enhancement of GPT2 expression was observed in leaves of FV-treated potato plants (Ezquer et al. 2010) and in leaves of Arabidopsis plants exposed to B. subtillis GB03 volatiles (Zhang et al. 2007). This is surprising because, although GPT2 has been shown to be essential for photosynthetic acclimation (Athanasiou et al. 2010), G6P/Pi transport is mainly restricted to heterotrophic tissues (Kammerer et al. 1998), where the imported G6P can be used for the synthesis of starch and fatty acids (Kang and Rawsthorne 1996, Zhang et al. 2008a) or to drive the OPPP (Bowsher et al. 2007). Thus, it is tempting to speculate that, as schematically illustrated in Figure 12, GPT2 would play a role in exporting G6P molecules derived from the starch breakdown when leaves are subjected to microbial volatile emissions.

Previous studies have shown that continuous exposure to high $\mathrm{CO}_{2}$ causes increase of starch content in leaves (Larios et al. 2001; Nafziger and Koller 1976). Because A. alternata produces $\mathrm{CO}_{2}$, it is likely that part of the starch accumulating in Arabidopsis leaves during FV exposure is ascribed to shortterm exposure to elevated $\mathrm{CO}_{2}$. Results presented in Figures 5 to 7 showing FV-promoted enhancement of 3PGA/Pi ratio and rapid NTRC-dependent reduction of AGP would indicate that post-translational modulation of AGP is partially involved in MIVOISAP. However, enhancement of total 3PGA/Pi ratio only occurs after approximately $6 \mathrm{~h}$ of FV treatment (Fig. 5), which does not explain the rapid accumulation of starch occurring upon FV exposure (Fig. 1). Furthermore, recent studies carried out in our lab have shown that previously termed "starch-less" or "zero-starch" adgl-1 and aps 1 AGP mutants are capable of accumulating almost WT starch levels and high levels of ADPG when exposed to FV (Bahaji et al. 2011), which would indicate that i) FV promote the expression of sources, other than AGP, of ADPG, and ii) AGP is not the main or sole target regulatory enzymatic step during MIVOISAP, although it is an essential enzyme for normal starch biosynthesis. Based on the results of Figure 8 showing that FV promote only a 10 -fold increase of starch content in SSIII and SSIV mutants, it is inferred that SSIII and SSIV are important targets of signaling cascades occurring upon FV sensing in the illuminated leaf. In this respect, it is important to note that SSIII contains a consensus motif for phosphoserine- or threoninebinding 14-3-3 proteins participating in environmentally responsive phosphorylation-regulated regulatory functions in plants (Sehnke et al. 2001). Furthermore, SS activity depends on redox status (Wieweg and de Fekete 1976). We are currently investigating the possible mechanisms regulating SS activity during MIVOISAP.

\section{MATERIALS AND METHODS}

\section{Plants, growth conditions, and sampling.}

The work was carried out using plants of Arabidopsis thaliana ('Columbia') and potato (Solanum tuberosum L. 'Desirée') cultured in solid MS medium which, unless otherwise indicated, was supplemented with $90 \mathrm{mM}$ sucrose. Arabidopsis mutants used in this work and their sources are listed in Supplementary Table 2. Plants were grown in growth chambers with a photoperiod of $16 \mathrm{~h}$ of white light (photons at $90 \mu \mathrm{mol} \mathrm{s}{ }^{-1} \mathrm{~m}^{-2}$ ) and $8 \mathrm{~h}$ of darkness at a constant temperature of $22^{\circ} \mathrm{C}$. Plants examined for their response to continuous monochromatic red (600 to $700 \mathrm{~nm}$ ), far-red (680 to $740 \mathrm{~nm}$ ), and blue (400 to 520 $\mathrm{nm})$ light were grown for $16 \mathrm{~h}$ in a growth chamber equipped with a Son-T Agro 400-W halogen lamp (Royal Philips Electronics, Amsterdam) filtered through one layer of either one of the following 0.3-mm polycarbonate filters: Supergel 19 for red light, Supergel 27 for far-red light, and Supergel 69 for blue light (Rosco Ibérica SA, Madrid). The halogen lamp provided a photosynthetically active radiation of $560 \mu \mathrm{E} \mathrm{m}^{-2} \mathrm{~s}^{-1}$. The photosynthetically active radiation under the different monochromatic lights was 283,80 , and $76 \mu \mathrm{E} \mathrm{m}^{-2} \mathrm{~s}^{-1}$ for red, far red, and blue filters, respectively. Alternaria alternata was cultured in petri dishes containing solid MS medium supplemented with $90 \mathrm{mM}$ sucrose. Synchronized microbial cultures without lids and petri dishes containing fully developed plants were placed into sterile plastic boxes and sealed as indicated by Ezquer and associates (2010). At the indicated incubation periods, leaves were harvested for biochemical and transcriptome analyses. As negative control, petri dishes containing plants were cultured in sealed plastic boxes together with petri dishes containing sterile microbial culture media. Harvested leaves were immediately freeze clamped and ground to a fine powder in liquid nitrogen with a pestle and mortar.

\section{Western blot analyses.}

For immunoblot analyses of AGP, protein samples were separated on $10 \%$ sodium dodecyl sulfate polyacrylamide gel electrophoresis (SDS-PAGE), transferred to nitrocellulose filters, and immunodecorated by using antisera raised against maize AGP as primary antibody and a goat anti-rabbit immunoglobulin $\mathrm{G}$ alkaline phosphatase conjugate (Sigma-Aldrich, St. Louis) as secondary antibody. Samples were extracted and 
separated on SDS-PAGE under both reducing and nonreducing conditions essentially as described by Hendriks and associates (2003) and Kolbe and associates (2005).

\section{Enzyme assays.}

All enzymatic reactions were carried out at $37^{\circ} \mathrm{C}$. Frozen powder $(1 \mathrm{~g})$ (discussed above) was resuspended at $4^{\circ} \mathrm{C}$ in 5 $\mathrm{ml}$ of $100 \mathrm{mM}$ HEPES (pH 7.5), $2 \mathrm{mM}$ EDTA, and $5 \mathrm{mM}$ dithiothreitol. The suspension was desalted and assayed for enzymatic activities. SuSy was assayed as described by BarojaFernández and associates (2009). $\beta$-Amylase was assayed as described by Liu and associates (2005). NR was assayed following the method of González and associates (2001). One unit (U) is defined as the amount of enzyme that catalyzes the production of $1 \mu \mathrm{mol}$ of product per minute.

\section{Analytical procedures.}

Starch was measured by using an amyloglucosydase-based test kit (Boehringer Manheim, Mannheim, Germany). 3PGA and $\mathrm{Pi}$ were determined as described by Lytovchenko and associates (2002). Maltose was measured as described by Ezquer and associates (2010). Determination of amino acid (Ser, Gly, Pro, and Arg) content was performed as described by Loiret and associates (2009). The results shown in the text were the mean \pm standard error of three independent experiments.

\section{Microarrays.}

Total RNA was extracted from frozen Arabidopsis leaves using the Trizol method according to the manufacturer's procedure (Invitrogen), following purification with RNeasy kit (Qiagen, Hilden, Germany). RNA amplification, labeling, and statistical data analysis were performed basically as described by Adie and associates (2007). Arabidopsis Gene Expression Microarray $4 \times 44 \mathrm{~K}$ (G2519; Agilent Technologies) were used for hybridization. Labeling and hybridization conditions were those described in the manual two-color microarray-based gene expression analysis of Agilent Technologies. Three independent biological replicates were hybridized for leaves from microbe-treated plants and from controls. Images from $\mathrm{Cy} 3$ and Hyper5 channels were equilibrated for intensity differences and captured with a GenePix 4000B scanner (Axon, Union City, CA, U.S.A.). Spots were quantified using GenePix software (Axon) and normalized using the Lowess method. The mean of the three replicate log-ratio intensities and their standard deviations were calculated and the expression data was statistically analyzed using the LIMMA Package (Smyth and Speed 2003). Functional characterization of the differentially expressed genes was done using the MapMan tool.

\section{Real-time quantitative PCR.}

Total RNA was extracted from Arabidopsis leaves as for microarray experiments. RNA was treated with RNase-free DNase (Takara, Shiga, Japan). RNA (1.5 $\mu \mathrm{g})$ was reverse transcribed using polyT primers and the Expand reverse transcriptase kit (Roche, Branchburg, NJ, U.S.A.) according to the manufacturer's instructions. RT-PCR reaction was performed using a 7900HT sequence detector system (Applied Biosystems, Foster City, CA, U.S.A.) with the SYBR Green PCR Master Mix (Applied Biosystems) according to the manufacturer's protocol. Each reaction was performed in triplicate with $0.4 \mu \mathrm{l}$ of the first-strand cDNA in a total volume of $20 \mu \mathrm{l}$. The specificity of the PCR amplification was checked with a heat dissociation curve (from 60 to $95^{\circ} \mathrm{C}$ ). Comparative threshold values were normalized to $18 \mathrm{~S}$ RNA internal control and compared to obtain relative expression levels. The specificity of the obtained RT-PCR products was controlled on $1.8 \%$ agarose gels. Primers used for RT-PCR are listed in Supplementary Table 3.

\section{ACKNOWLEDGMENTS}

J. Li and I. Ezquer contributed equally to this work. This research was partially supported by the grants BIO2007-63915 and BIO2010-18239 from the Comisión Interministerial de Ciencia y Tecnología and Fondo Europeo de Desarrollo Regional (Spain), and by Iden Biotechnology S.L. I. Ezquer acknowledges a pre-doctoral fellowship from the Spanish Ministry of Education and Science. M. Ovecka was partly supported by grant number 2/0200/10 from the Grant Academy VEGA. We thank C. Hannah (University of Florida), who kindly provided us the antibody raised against maize AGP; and F. J. Cejudo and C. Gotor (IBVF, Sevilla), who kindly provided seed of Arabidopsis mutants used in this study.

\section{LITERATURE CITED}

Adie, B. A. T., Pérez-Pérez, J., Pérez-Pérez, M., Godoy, M., SánchezSerrano, J. J., Schmelz, E.A., and Solano, R. 2007. ABA is an essential signal for plant resistance to pathogens affecting JA biosynthesis and the activation of defenses in Arabidopsis. Plant Cell 19:1665-1681.

Appenroth, K.-J., and Gabrys, H. 2003. Ion antagonism between calcium and magnesium in phytochrome-mediated degradation of storage starch in Spirodela polyrhiza. Plant Sci. 165:1261-1265.

Athanasiou, K., Dyson, B. C., Webster, R. E., and Johnson, G. N. 2010. Dynamic acclimation of photosynthesis increases plant fitness in changing environments. Plant Physiol. 152:366-373.

Baena-González, E., and Sheen, J. 2008. Convergent energy and stress signalling. Trends Plant Sci. 13:474-482.

Baena-González, E., Rolland, F., Thevelein, J. M., and Sheen, J. 2007. A central integrator of transcription networks in plant stress and energy signalling. Nature 448:938-943.

Bahaji, A., Li, J., Ovecka, M., Ezquer, I., Muñoz, F. J., Baroja-Fernández, E., Romero, J. M., Almagro, G., Montero, M., Hidalgo, M., Sesma, M. T., and Pozueta-Romero, J. Arabidopsis thaliana mutants lacking ADPglucose pyrophosphorylase accumulate starch and ADP-glucose: Further evidences for the occurrence of important sources, other than ADPglucose pyrophosphorylase, of ADP-glucose linked to leaf starch biosynthesis. Plant Cell Physiol. 52:1162-1176.

Baroja-Fernández, E., Muñoz, F. J., Montero, M., Etxeberria, E., Sesma, M. T., Ovecka, M., Bahaji, A., Ezquer, I., Li, J., Prat, S., and PozuetaRomero, J. 2009. Enhancing sucrose synthase activity in transgenic potato (Solanum tuberosum L.) tubers results in increased levels of starch, ADPglucose and UDPglucose and total yield. Plant Cell Physiol. 50:1651-1662.

Barratt, D. H. P., Derbyshire, P., Findlay, K., Pike, M., Wellner, N., Lunn, J., Feil, R., Simpson, C., Maule, A. J., and Smith, A. M. 2009. Normal growth of Arabidopsis requires cytosolic invertase but not sucrose synthase. Proc. Natl. Acad. Sci. U.S.A. 106:13124-13129.

Belanger, A. E., and Hatfull, G. F. 1999. Exponential-phase glycogen recycling is essential for growth of Mycobacterium smegmatis. J. Bacteriol. 181:6670-6678.

Berger, S., Sinha, A. K., and Roitsch, T. 2007. Plant physiology meets phytopathology: Plant primary metabolism and plant-pathogen interactions. J. Exp. Bot. 58:4019-4026.

Bermúdez, M. A., Páez-Ochoa, M. A., Gotor, C., and Romero, L. C. 2010. Arabidopsis $S$-sulfocysteine activity is essential for chloroplast function and long-day light-dependent redox control. Plant Cell 22:403-416.

Bonfig, K. B., Schreiber, U., Gabler, A., Roitsch, T., and Berger, S. 2006. Infection with virulent and avirulent $P$. syringae strains differentially affects photosynthesis and sink metabolism in Arabidopsis leaves Planta 225:1-12.

Bowsher, C. G., Lacey, A. E., Hanke, G. T., Clarkson, D. T., Saker, L. R., Stulen, I., and Emes, M. J. 2007. The effect of Glc6P uptake and its subsequent oxidation within pea root plastids on nitrite reduction and glutamate synthesis. J. Exp. Bot. 58:1109-1118.

Cartieaux, F., Contesto, C., Gallou, A., Desbrosses, G., Kopka, J., Taconnat, L., Renou, J.-P., and Touraine, B. 2008. Simultaneous interaction of Arabidopsis thaliana with Bradyrhizobium sp. Strain ORS278 and Pseudomonas syringae pv. tomato DC3000 leads to complex transcriptome changes. Mol. Plant-Microbe Interact. 21:244-259.

Chen, M., Chory, J., and Fankhauser, C. 2004. Light signal transduction in higher plants. Annu. Rev. Genet. 38:87-117.

Chou, H., Bundock, N., Rolfe, S., and Scholes, J. 2000. Infection of Arabidopsis thaliana leaves with Albugo candida causes a reprogramming of host metabolism. Mol. Plant Pathol. 1:99-113.

Crane, F. L., Sun, I. L., Barr, R., and Löw, H. 1991. Electron and proton transport across the plasma membrane. J. Bioenerg. Biomembr. 23:773803.

Davis, S. J., Kurepa, J., and Viestra, R. D. 1999. The Arabidopsis thaliana HY1 locus, required for phytochrome-chromophore biosynthesis, encodes 
a protein related to heme oxygenases. Proc. Natl. Acad. Sci. U.S.A. 96:6541-6546.

Eckey, C., Korell, M., Leib, K., Biedenkopf, D., Jansen, C., Lagnen, G., and Kogel, K.-H. 2004. Identification of powdery mildew-induced barley genes by cDNA-AFLP: Functional assessment of an early expressed MAP kinase. Plant Mol. Biol. 55:1-15.

Edner, C., Li, J., Albrecht, T., Mahlow, S., Hejazi, M., Hussain, H., Kaplan, F., Guy, C., Smith, S. M., Steup, M., and Ritte, G. 2007. Glucan, water dikinase activity stimulates breakdown of starch granules by plastidial $\beta$-amylases. Plant Physiol. 145:17-28.

Elzenga, J. T., Staal, M., and Prins, H. B. 2000. Modulation by phytochrome of the blue light-induced extracellular acidification by leaf epidermal cells of pea (Pisum sativum L.): A kinetic analysis. Plant J. 22:377-389.

Essmann, J., Bones, P., Weis, E., and Scharte, J. 2008. Leaf carbohydrate metabolism during defense. Plant Signal. Behav. 3:885-887.

Eydallin, G., Viale, A. M., Morán-Zorzano, M. T., Muñoz, F. J., Montero, M., Baroja-Fernández, E., and Pozueta-Romero, J. 2007. Genome-wide screening of genes affecting glycogen metabolism in Escherichia coli K-12. FEBS (Fed. Eur. Biochem. Soc.) Lett. 581:2947-2953.

Ezquer, I., Li., J., Ovecka, M., Baroja-Fernández, E., Muñoz, F. J., Montero, M., Díaz de Cerio, J., Hidalgo, M., Sesma, M. T., Bahaji, A., Etxeberría, E., and Pozueta-Romero, J. 2010. Microbial volatile emissions promote accumulation of exceptionally high levels of starch in leaves in monoand di-cotyledonous plants. Plant Cell Physiol. 51:1674-1693.

Fabro, G., Di Rienzo, J. A., Voigt, C. A., Savchenko, T., Dehesh, K., Somerville, S., and Alavarez, M. E. 2008. Genome-wide expression profiling Arabidopsis at the stage of Golovinomyces cichoracearum haustorium formation. Plant Physiol. 146:1421-1439.

Fotopoulos, V., Gilbert, M. J., Pittman, J. K., Marvier, A. C., Buchanan, A. J., Sauer, N., Hall, J. L., and Williams, L. E. 2003. The monosaccharide transporter gene, AtSTP4, and the cell-wall invertase, Atbetafruct1, are induced in Arabidopsis during infection with the fungal biotroph Erysiphe cichoracearum. Plant Physiol. 132:821-829.

Fritzius, T., Aeschbacher, R., Wiemken, A., and Wingler, A. 2001. Induction of ApL3 expression by trehalose complements the starch-deficient Arabidopsis mutant adg2-1 lacking ApL1, the large subunit of ADPglucose pyrophosphorylase. Plant Physiol. 126:883-889.

Fulton, D. C., Stettler, M., Mettler, T., Vaughan, C. K., Li, J., Francisco, P., Gil, M., Reinhold, H., Eicke, S., Messerli, G., Dorken, G., Halliday, K. Smith, A. M., Smith, S. M., and Zeeman, S. C. 2008. $\beta$-Amylase4, a noncatalytic protein required for starch breakdown, acts upstream of three active $\beta$-amylases in Arabidopsis chloroplasts. Plant Cell 20:1040-1058.

Geigenberger, P., Lerchl, J., Stitt, M., and Sonnewald, U. 1996. Phloemspecific expression of pyrophosphatase inhibits long distance transport of carbohydrates and amino acids in tobacco plants. Plant Cell Environ. 19:43-55.

Geigenberger, P., Kolbe, A., and Tiessen, A. 2005. Redox regulation of carbon storage and partitioning in response to light and sugars. J. Exp. Bot. 56:1469-1479.

González, E. M., Cabrerizo, P. M., Royuela, M., Aparicio-Tejo, P. M., and Arrese-Igor, C. 2001. Nitrate reduction in tendrils of semi-leafless peas. Physiol. Plant. 111:329-335.

Guedon, E., Desvaux, M., and Petitdemange, H. 2000. Kinetic analysis of Clostridium cellulolyticum carbohydrate metabolism: Importance of glucose 1-phosphate and glucose 6-phosphate branch points for distribution of carbon fluxes inside and outside cells as revealed by steadystate continuous culture. J. Bacteriol. 182:2010-2017.

Hahlbrock, K., Bednarek, P., Ciolkowski, I., Hamberger, B., Heise, A., Liedgens, H., Logemann, E., Nurnberger, T., Schmelzer, E., Somssich, I. E., and Tan, J. 2003. Non-self recognition, transcriptional reprogramming, and secondary metabolite accumulation during plant/pathogen interactions. Proc. Natl. Acad. Sci. U.S.A. 100:14569-14576.

Hendriks, J. H. M., Kolbe, A., Gibon, Y., Stitt, M., and Geigenberger, P. 2003. ADP-glucose pyrophosphorylase is activated by posttranslational redox-modification in response to light and to sugars in leaves of Arabidopsis and other plant species. Plant Physiol. 133:838-849.

Kai, M., and Piechulla, B. 2009. Plant growth promotion due to rhizobacterial volatiles-An effect of $\mathrm{CO}_{2}$ ? FEBS (Fed. Eur. Biochem. Soc.) Lett. 583:3473-3477

Kaiser, W. M., and Huber, S. C. 2001. Post-translational regulation of nitrate reductase: Mechanism, physiological relevance and environmental triggers. J. Exp. Bot. 52:1981-1989.

Kammerer, B., Fischer, K., Hilpert, B., Schubert, S., Gutensohn, M., Weber A., and Flügge, U.-I. 1998. Molecular characterization of a carbon transporter in plastids from heterotrophic tissues: The glucose 6-phosphate/phosphate antiporter. Plant Cell 10:105-117.

Kang, F., and Rawsthorne, S. 1996. Metabolism of glucose-6-phosphate and utilization of multiple metabolites for fatty acid synthesis by plastids from developing oilseed rape embryos. Planta 199:321-327.

Kaplan, F., and Guy, C. L. 2004. $\beta$-Amylase induction and the protective role of maltose during temperature shock. Plant Physiol. 135:1674-1684.

Kaplan, F., and Guy, C. L. 2005. RNA interference of Arabidopsis betaamylase 8 prevents maltose accumulation upon cold shock and increases sensitivity of PSII photochemical efficiency to freezing stress. Plant J. 44:730-743.

Keiller, D., and Smith, H. 1989. Control of carbon partitioning by light quality mediated by phytochrome. Plant Sci. 63:25-29.

Kinoshita, T., Doi, M., Suetsugu, N., Kagawa, T., Wada, M., and Shimazaki, K. 2001. phot1 and phot 2 mediate blue light regulation of stomatal opening. Nature 414:656-660.

Kleczkowski, L. A. 1999. A phosphoglycerate to inorganic phosphate ratio is the major factor in controlling starch levels in chloroplasts via ADPglucose pyrophosphorylase regulation. FEBS (Fed. Eur. Biochem. Soc.) Lett. 448:153-156.

Kohchi, T., Mukougawa, K., Frankenberg, N., Masuda, M., Yokota, A., and Lagarias, J. C. 2001. The Arabidopsis HY2 gene encodes phytochromobilin synthase, a ferredoxin-dependent biliverdin reductase. Plant Cell 13:425-436.

Kolbe, A., Tiessen, A., Schluepmann, H., Paul, M., Ulrich, S., and Geigenberger, P. 2005. Trehalose 6-phosphate regulates starch synthesis via posttranslational redox activation of ADP-glucose pyrophosphorylase. Proc. Natl. Acad. Sci. U.S.A. 102:11118-11123.

Laby, R. J., Kim, D., and Gibson, S. I. 2001. The ram1 mutant of Arabidopsis exhibits severely decreased $\beta$-amylase activity. Plant Physiol. 127:1798-1807.

Lao, N. T., Schoneveld, O., Mould, R. M., Hibberd, J. M., Gray, J. C., and Kavanagh, T. A. 1999. An Arabidopsis gene encoding a chloroplasttargeted $\beta$-amylase. Plant J. 20:519-527.

Larios, B., Agüera, E., de la Haba, P., Pérez-Vicente, R., and Maldonado, J. M. 2001. A short-term exposure of cucumber plants to rising atmospheric $\mathrm{CO}_{2}$ increases leaf carbohydrate content and enhances nitrate reductase expression and activity. Planta 212:305-312.

Lemaire, S. D., Michelet, L., Zaffagnini, M., Massot, V., and IssakidisBourguet, E. 2007. Thioredoxins in chloroplasts. Curr. Genet. 51:343-365.

Lillo, C., Meyer, C., Lea, U. S., Provan, F., and Oltedal, S. 2004. Mechanism and importance of post-translational regulation of nitrate reductase. J. Exp. Bot. 55:1275-1282.

Liu, X., Zhang, S., Shan, X., and Zhu Y. G. 2005. Toxicity of arsenate and arsenite on germination, seedling growth and amylolitic activity of wheat. Chemosphere 61:293-301.

Loiret, F. G., Grimm, B., Hajirezaei, M. R., Kleiner, D., and Orterga, E. 2009. Inoculation of sugarcane with Pantoea sp. Increases amino acid contents in shoot tissues; serine, alanine, glutamine and asparagines permite concomitantly ammonium excretion and nitrogenase activity of the bacterium. J. Plant Physiol. 166:1152-1161.

Lu, Y., Gehan, J. P., and Sharkey, T. D. 2005. Daylength and circadian effects on starch degradation and maltose metabolism. Plant Physiol. 138:2280-2291

Lunn, J. E., Feil, R., Hendriks, J. H. M., Gibon, Y., Morcuende, R., Osuna, D., Scheible, W-R., Carillo, P., Hajirezaei, M-R., and Stitt, M. 2006. Sugar-induced increases in trehalose 6-phosphate are correlated with redox activation of ADPglucose pyrophosphorylase and higher rates of starch synthesis in Arabidopsis thaliana. Biochem. J. 397:139-148.

Lytovchenko, A., Bieberich, K., Willmitzer, L., and Fernie, A. R. 2002. Carbon assimilation and metabolism in potato leaves deficient in plastidial phosphoglucomutase. Planta 215:802-811.

Meyer, Y., Siala, W., Bashandy, T., Riondet, C., Vignols, F., and Reichheld, J. P. 2008. Glutaredoxins and thioredoxins in plants. Biochim. Biophys. Acta 1783:589-600.

Michalska, J., Zauber, H., Buchanan, B. B., Cejudo, F. J., and Geigenberger, P. 2009. NTRC links built-in thioredoxin to light and sucrose in regulating starch synthesis in chloroplasts. Proc. Natl. Acad. Sci. U.S.A. 106:9908-9913.

Michel, K., Abderhalden, O., Bruggmann, R., and Dudler, R. 2006. Transcriptional changes in powdery mildew infected wheat and Arabidopsis leaves undergoing syringolin-triggered hypersensitive cell death at infection sites. Plant Mol. Biol. 62:561-578.

Mikkelsen, R., Mutenda, K. E., Mant, A., Schürmann, P., and Blennow, A. 2005. $\alpha$-Glucan, water dikinase (GWD): A plastidic enzyme with redoxregulated and coordinated catalytic activity and binding affinity. Proc. Natl. Acad. Sci. U.S.A. 102:1785-1790.

Monte, E., Tepperman, J. M., Al-Sady, B., Kaczorowski, K. A., Alonso, J M., Ecker, J. R., Li, X., Zhang, Y., and Quail, P. H. 2004. The phytochrome-interacting transcription factor, PIF3, acts early, selectively, and positively in light-induced chloroplast development. Proc. Natl. Acad. Sci. U.S.A. 101:16091-16098.

Montero, M., Eydallin, G., Viale, A. M., Almagro, G., Muñoz, F. J., Rahimpour, M., Sesma, M. T., Baroja-Fernández, E., and Pozueta- 
Romero, J. 2009. Escherichia coli glycogen metabolism is controlled by the PhoP-PhoQ regulatory system at submillimolar environmental $\mathrm{Mg}^{2+}$ concentrations, and is highly interconnected with a wide variety of cellular processes. Biochem. J. 424:129-141.

Moreno-Bruna, B., Baroja-Fernández, E., Muñoz, F. J., BastarricaBerasategui, A., Zandueta-Criado, A., Rodríguez-López, M., Lasa, I. Akazawa, T., and Pozueta-Romero, J. 2001. Adenosine diphosphate sugar pyrophosphatase prevents glycogen biosynthesis in Escherichia coli. Proc. Natl. Acad. Sci. U.S.A. 98:8128-8132.

Muñoz, F. J., Baroja-Fernández, E., Morán-Zorzano, M. T., Viale, A. M., Etxeberria, E., Alonso-Casajús, N., and Pozueta-Romero, J. 2005. Sucrose synthase controls the intracellular levels of ADPglucose linked to transitory starch biosynthesis in source leaves. Plant Cell Physiol. 46:1366-1376.

Nafziger, E. D., and Koller, H. R. 1976. Influence of leaf starch concentration on $\mathrm{CO}_{2}$ assimilation in soybean. Plant Physiol. 57:560-563.

Pageau, K., Reisdorf-Cren, M., Morot-Gaudry, J.-F., and MasclauxDaubresse, C. 2006. The two senescence-related markers, GS1 (cytosolic glutamine synthase) and $G D H$ (glutamate dehydrogenase), involved in nitrogen mobilization, are differentially regulated during pathogen attack and by stress hormones and reactive oxygen species in Nicotiana tabacum L. leaves. J. Exp. Bot. 57:547-557.

Paré, P. W., Farag, M. A., Krishnamachari, V., Zhang, H., Ryu, C. M., and Kloepper, J. W. 2005. Elicitors and priming agents initiate plant defense responses. Photosynth. Res. 85:149-159.

Pérez-Ruiz, J. M., and Cejudo, F. J. 2009. A proposed reaction mechanism for rice NADPH thioredoxin reductase C, an enzyme with protein disulfide reductase activity. FEBS (Fed. Eur. Biochem. Soc.) Lett. 583:13991402.

Pulido, P., Spínola, M. C., Kirchsteiger, K., Guinea, M., Pascual, M. B., Sahrawy, M., Sandalio, L. M., Dietz, K.-J., González, M., and Cejudo, F. J. 2010. Functional analysis of the pathways for 2-Cys peroxiredoxin reduction in Arabidopsis thaliana chloroplasts. J. Exp. Bot. 61:40434045.

Ramon, M., Rolland, F., Thevelein, J. M., Van Dijck, P., and Leyman, B. 2007. ABI4 mediates the effects of exogenous trehalose on Arabidopsis growth and starch breakdown. Plant Mol. Biol. 63:195-206.

Roldán, I., Wattebled, F., Mercedes Lucas, M., Delvalle, D., Planchot, V., Jimenez, S., Perez, R., Ball, S., D’Hulst, C., and Mérida, A. 2007. The phenotype of soluble starch synthase IV defective mutants of Arabidopsis thaliana suggests a novel function of elongation enzymes in the control of starch granule formation. Plant J. 49:492-504.

Rösler, J., Klein, I., and Zeidler, M. 2007. Arabidopsis fhl/fhyl double mutant reveals a distinct cytoplasmic action of phytochrome A. Proc. Natl. Acad. Sci. U.S.A. 104:10737-10742.

Ryu, C. M., Farag, M. A., Hu, C. H., Reddy, M. S., Wei, H. X., Pare, P. W., and Kloepper, J. W. 2003. Bacterial volatiles promote growth in Arabidopsis. Proc. Natl. Acad. Sci. U.S.A. 100:4927-4932.

Ryu, C. M., Farag, M. A., Hu, C. H., Reddy, M. S., Kloepper, J. W., and Pare, P. W. 2004. Bacterial volatiles induce systemic resistance in Arabidopsis. Plant Physiol. 134:1017-1026.

Scharte, J., Schön, H., and Weis, E. 2005. Photosynthesis and carbohydrate metabolism in tobacco leaves during an incompatible interaction with Phytophthora nicotianae. Plant Cell Environ. 28:1421-1435.

Scheible, W.-R., González-Fontes, A., Lauerer, M., Müller-Röber, B., Caboche, M., and Stitt, M. 1997. Nitrate acts as a signal to induced organic acid metabolism and repress starch metabolism in tobacco. Plant Cell 9:783-798.

Schluepmann, H., Pellny, T., van Dijken, A., Smeekens, S., and Paul, M. 2003. Trehalose 6-phosphate is indispensable for carbohydrate utilization and growth in Arabidopsis thaliana. Proc. Natl. Acad. Sci. U.S.A. 100:6849-6854.

Schluepmann, H., van Dijken, A., Aghdasi, M., Wobbes, B., Paul, M., and Smeekens, S. 2004. Trehalose mediated growth inhibition of Arabidopsis seedlings is due to trehalose-6-phosphate accumulation. Plant Physiol. 135:879-890.

Schulz, S., and Dickschat, J. S. 2007. Bacterial volatiles: The smell of small organisms. Nat. Prod. Rep. 24:814-842.

Sehnke, P. C., Chung, W.-J., Wu, K., and Ferl, R. J. 2001. Regulation of starch accumulation by granule-associated plant 14-3-3 proteins. Proc. Natl. Acad. Sci. U.S.A. 98:765-770.

Smith, S. M., Fulton, D. C., Chia, T., Thrneycroft, D., Chapple, A., Dunstan, H, Hylton, C., Zeeman, S. C., and Smith, A. M. 2004. Diurnal changes in the transcriptome encoding enzymes of starch metabolism provide evidence for both transcriptional and posttranscriptional regulation of starch metabolism in Arabidopsis leaves. Plant Physiol. 136:2687-2699.

Smyth, G. K., and Speed, T. 2003. Normalization of cDNA microarray data. Methods 31:265-273.

Sokolov, L. N., Déjardin, A., and Kleczkowski, L. A. 1998. Sugars and light/dark exposure trigger differential regulation of ADP-glucose pyrophosphorylase genes in Arabidopsis thaliana (thale cress). Biochem. J. 336:681-687.

Sparla, F., Costa, A., Schiavo, F. L., Pupillo, P., and Trost, P. 2006. Redox regulation of a novel plastid-targeted $\beta$-amylase of Arabidopsis. Plant Physiol. 141:840-850.

Szabados, L., and Savouré, A. 2009. Proline: A multifunctional amino acid. Trends Plant Sci. 15:89-97.

Szydlowski, N., Ragel, P., Raynaud, S., Roldán, I., Montero, M., Lucas, M. M., Planchot, V., Muñoz, F. J., Ovecka, M., Bahaji, A., PozuetaRomero, J., D'Hulst, C., and Mérida, A. 2009. Starch granule initiation in Arabidopsis requires the presence of either class IV or class III starch synthase. Plant Cell 21:2443-2457.

Takagi, S., Kong, S.-G., Mineyuki, Y., and Furuya, M. 2003. Regulation of actin-dependent cytoplasmic motility by type II phytochrome occurs within seconds in Vallisneria gigantean epidermal cells. Plant Cell 15:331-345.

Tepperman, J. M., Zhu, T., Chang, H-S., Wang, X., and Quail, P. H. 2001. Multiple transcription-factor genes are early targets of phytochrome A signalling. Proc. Natl. Acad. Sci. U.S.A. 98:9437-9442.

Tepperman, J. M., Hwang, Y.-S., and Quail, P. H. 2006. phyA dominates in transduction of red-light signals to rapidly responding genes at the initiation of Arabidopsis seedling de-etiolation. Plant J. 48:728-742.

Thimm, O., Bläsing, O., Gibon, Y., Nagel, A., Meyer, S., Krüger, P., Selbig, J., Müller, L. A., Rhee, S. Y., and Stitt, M. 2004. MAPMAN: A userdriven tool to display genomics data sets onto diagrams of metabolic pathway and other biological processes. Plant J. 37:914-939.

Valerio, C., Costa, A., Marri, L., Issakidis-Bourguet, E. Pupillo, P., Trost, P., and Sparla, F. 2010. Thioredoxin-regulated $\beta$-amylase (BAM1) triggers diurnal starch degradation in guard cells, and in mesophyll cells under osmotic stress. J. Exp. Bot. 62:545-555.

Vespermann, A., Kai, M., and Piechulla, B. 2007. Rhizobacterial volatiles affect the growth of fungi and Arabidopsis thaliana. Appl. Environ. Microbiol. 73:5639-5641.

Wattebled, F., Dong, Y., Dumez, S., Delvallé, D., Planchot, V., Berbazy, P., Vyas, D., Colonna, P., Chatterjee, M., Ball, S., and D'Hulst, C. 2005. Mutants of Arabidopsis lacking a chloroplastic isoamylase accumulate phytoglycogen and an abnormal form of amylopectin. Plant Physiol. 138:184-195.

Westram, A., Lloyd, J. R., Roessner, U., Riesmeier, J. W., and Kossmann, J. 2002. Increases of 3-phosphoglyceric acid in potato plants through antisense reduction of cytoplasmic phosphoglycerate mutase impairs photosynthesis and growth, but does not increase starch contents. Plant Cell Environ. 25:1133-1143.

Wieweg, G. H., and de Fekete, M. A. 1976. Dependence of starch synthase activity from maize leaves on light, $\mathrm{pH}$ and redox state. Acta Physiol. Lat. Am. 26:415-423.

Wilson, W. A., Roach, P. J., Montero, M., Baroja-Fernández, E., Muñoz, F. J., Eydallin, G., Viale, A. M., and Pozueta-Romero, J. 2010. Regulation of glycogen metabolism in yeast and bacteria. FEMS (Fed. Eur. Microbiol. Soc.) Microbiol. Rev. 34:952-985.

Wingler, A., Fritzius, T., Wiemken, A., Boller, T., and Aeschbacher, R. A. 2000. Trehalose induces the ADP-glucose pyrophosphorylase gene, ApL3, and starch synthesis in Arabidopsis. Plant Physiol. 124:105-111.

Yu, T.-S., Zeeman, S. C., Thorneycroft, D., Fulton, D. C., Dunstan, H., Lue, W.-L., Hegemann, B., Tung, S.-Y., Umemoto, T., Chapple, A., Tsai, D.-L., Wang, S-M., Smith, A. M., Chen, J., and Smith, S. M. 2005. $\alpha$-amylase is not required for breakdown of transitory starch in Arabidopsis leaves. J. Biol. Chem. 280:9773-9779.

Zhang, H., Kim, M.-S., Krishnamachari, V., Payton, P., Sun, Y., Grimson, M., Farag, M. A., Ryu, C.-M., Allen, R., Melo, I. S., and Paré, P. W. 2007. Rhizobacterial volatile emissions regulate auxin homeostasis and cell expansion in Arabidopsis. Planta 226:839-851.

Zhang, L., Häusler, R. E., Greiten, C., Hajirezaei, M.-R., Haferkamp, I., Neuhaus, H. E., Flügge, U.-I., and Ludewig, F. 2008a. Overriding the co-limiting import of carbon and energy into tuber amyloplasts increases the starch content and yield of transgenic potato plants. Plant Biotechnol. J. 6:453-464.

Zhang, H., Xie, X., Kim, M.-S., Kornyeyev, D. A., Holaday, S., and Paré, P. W. 2008b. Soil bacteria augment Arabidopsis photosynthesis by decreasing glucose sensing and abscisic acid levels in planta. Plant J. 56:264-273.

Zhang, H., Sun, Y., Xie, X., Kim, M-S., Dowd, S. E., and Paré, P. W. 2009. A soil bacterium regulates plant acquisition of iron via deficiencyinducible mechanisms. Plant J. 58:568-577.

\section{AUTHOR-RECOMMENDED INTERNET RESOURCE}

MapMan tool: gabi.rzpd.de/projects/MapMan 